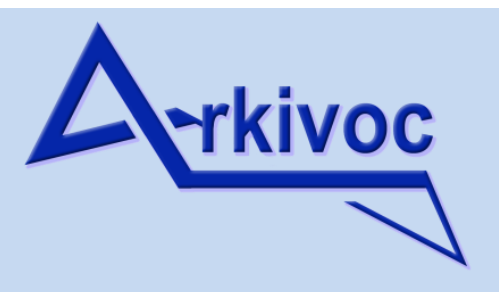

Archive for

Organic Chemistry
The Free Internet Journal

for Organic Chemistry
Review

Arkivoc 2017, part i, 117-147

\title{
Selective fluorination of natural products
}

\author{
Paige J. Monsen and Frederick A. Luzzio* \\ Department of Chemistry, University of Louisville, 2320 South Brook Street, \\ Louisville, KY 40292 United States \\ Email: frederick.luzzio@louisville.edu
}

Received 11-01-2016

Accepted 12-08-2016

Published on line 04-02-2017

\begin{abstract}
Compounds derived from natural sources including animals, plants, and micro-organisms have been widely used for pharmaceuticals, materials, and agrochemicals. The use of these natural products has grown increasingly over the years and the demand for more improved, biologically active, and safer derivatives of natural products has been investigated by many researchers in the areas of synthetic and medicinal chemistry. Due to the unique characteristics of fluorinated compounds, and the increased or more favorable biological activity which usually accompanies fluorinated analogues of medicinally-important compounds, the fluorination of natural products has gained much attention. This review aims at exploring the range of specific natural product types that have been selectively fluorinated as well as how fluorination was expected to affect their biological activities and physiochemical properties.
\end{abstract}

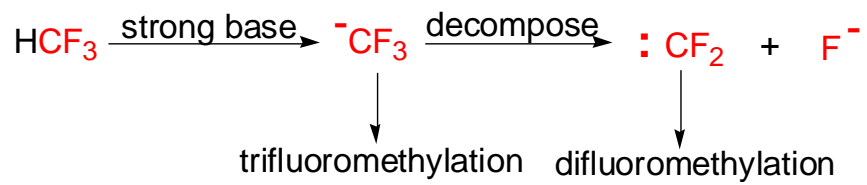

Keywords: Natural products, fluorination, biological activity, halogenation 


\section{Table of Contents}

1. Introduction

2. Fluorination Reagents

2.1 Nucleophilic fluorination reagents

2.2 Electrophilic fluorination reagents

3. Terpenoids

4. Lipid Natural Products

4.1 Aliphatic natural products

4.2 Acetogenins

4.3 Steroids

5. Polyketides

6. Carbohydrates

6.1 Hexopyranosides

6.2 Nucleosides

7. General Oxygen Heterocycles

7.1 Furanoids/benzofuranoids

7.2 Pyranoids/benzopyranoids

8. Aromatic and Cyclic Ketones

9. Amino Acids and Peptides

10. Alkaloids and Nitrogen Heterocycles

11. Tannins/Lignans

12. Conclusions

\section{Introduction}

Utilizing natural products in the medicinal world has proven to be beneficial in society today. With many pharmaceuticals containing natural products or natural product derivatives as the biologically active compounds of interest, the search to improve these compounds has drawn a great deal of attention. Fluorination of these compounds has been one area of research that has grown tremendously and has been limited by only the types of fluorination reagents, their availability, and the sensitivity of the natural substrate. Fluorine itself exhibits potent characteristics, including a small van der Waals radius of $147 \mathrm{ppm}$ and the highest electronegativity of 3.98 in the periodic table. ${ }^{2}$ Compounds that have been fluorinated therefore display beneficial properties that set them apart. Metabolic stability, binding affinity, lowering of surface tension, hydrophobicity and lipophobicity are just some of the properties that accompany the fluorination of a compound thereby contributing to unique biological properties. ${ }^{3}$ This overview provides a visualization of several advances in the selective fluorination of natural product with referenced works ranging from the 1980 s to the present year. While late-stage fluorinations are emphasized, synthetic schemes showing incorporation of fluorinated intermediates are included for contrast. ${ }^{4,5,6}$ 


\section{Fluorinating Reagents}

\subsection{Nucleophilic fluorinating reagents}

Nucleophilic fluorination is characterized as a fluoride ion behaving as a nucleophile which attacks an electrophilic substrate or its activated complex. Both alkali metal fluorides and HF-based reagents have been utilized as fluoride sources (Figure 1).

\section{$\mathrm{HF} \quad \mathrm{HF}_{-} \mathrm{SbF}_{5} \quad \mathrm{KF}$}

Figure 1. Alkali-metal fluorides and HF-based reagents.

The most straightforward example is an alkyl chain which bears a suitable leaving group that can readily react with a nucleophilic fluoride ion (Scheme 1).

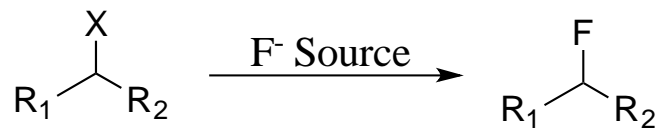

Scheme 1. Nucleophilic fluorination reaction.

Although many traditional nucleophilic fluorination reagents have been used in the past, the majority of natural products have either been fluorinated by HF-based reagents or more commonly were selectively fluorinated by deoxofluorinating reagents. The deoxofluorinating reaction is a modified nucleophilic fluorinating reaction which involves the generation of an activated alcohol as well as a fluoride ion. ${ }^{7}$ The fluoride ion participates in a nucleophilic attack, generally an $S_{N} 2$ reaction, to produce an alkyl fluoride (Scheme 2). With this form of selective fluorination, many deoxofluorinating reagents have been developed. The reagents that have been developed for such reactions, including DAST ${ }^{8}$, Deoxofluor ${ }^{\circledR}{ }^{9}$, Fluolead ${ }^{\mathrm{TM}}{ }^{10}$, and Phenofluor ${ }^{\mathrm{TM}} 11$ are $^{10}$ shown in Figure 2.

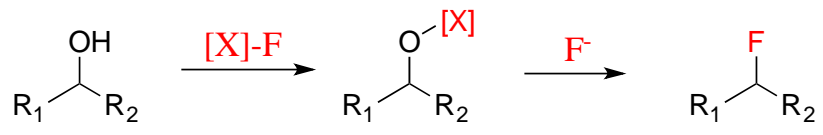

Scheme 2. Deoxofluorinating Reaction.

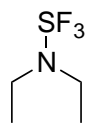

DAST

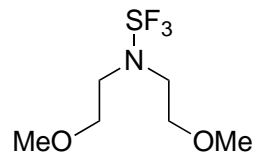

Deoxofluor $^{\circledR}$

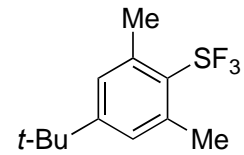

Fluolead $^{\mathrm{TM}}$

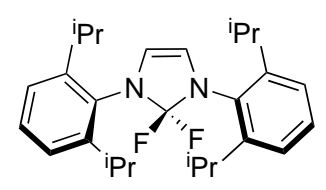

PhenoFluor $^{\text {TM }}$

Figure 2. Deoxofluorination reagents. 


\subsection{Electrophilic fluorinating reagents}

An electrophilic fluorination reaction is characterized as the fluorine source behaving as an electrophile and the substrate is that of a nucleophile. The most common form of $\mathrm{F}^{+}$originates from fluorine gas, where the electrophilic fluorinating reagents are highly oxidizing, ${ }^{12}$ including fluorine gas and hypofluorites. The advance in reagents that can react via electrophilic fluorination and embody a certain specificity of conditions has not only improved the selectivity of fluorination but has also improved the tolerance of functional groups. ${ }^{13}$ The developments of reagents such as $N$-fluoropyridium salts (FP-T300) ${ }^{14}, N$-fluorobis(phenyl)sulfonimide (NFSI) ${ }^{15}$, 1-chloromethyl-4-fluoro-1,4-diazoniabicyclo-[2.2.2] octane bis(tetrafluoroborate) (Selectfluor ${ }^{\circledR}$, F-TEDA-BF $_{4}$ ), ${ }^{16}$ and derivative F-TEDA-PF ${ }^{17}$ have been great innovations to the introduction of a fluorine atom (Figure 3).

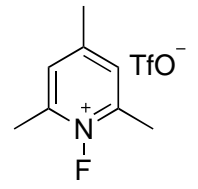

FP-T300<smiles>O=S(=O)(Oc1ccccc1)N(F)S(=O)(=O)c1ccccc1</smiles>

NFSI

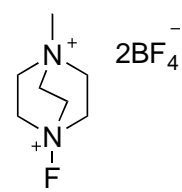

Selectfluor ${ }^{\circledR}$

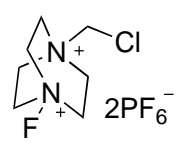

F-TEDA-PF 6

Figure 3. Electrophilic fluorinating reagents.

\section{Terpenoids}

Terpenoids, the largest class of natural products, are diverse in origin, structure and function. Whether derived from plant or animal, such compounds have roles involved in an organism's defense mechanism as well as a form of interaction or chemical communication between organisms. With many terpenes containing natural biological activities, the derivatization of such compounds can lead to enhancing these features and potentially increasing drug like properties. The simplest of terpenoids are the monoterpenes, which consist of two isoprene units and are highly aromatic molecules with limited functionality. Borneol and camphor, both bicyclics, are amongst the simplest of terpenes that have been fluorinated. Borneol $\mathbf{1}$ was fluorinated by the Middleton group while investigating fluorination reactions which utilize DAST. ${ }^{8}$ As expected, carbonium ion type rearrangements are problems that can occur while replacing an alcohol group with a fluoride. Although carbonium ion type rearrangements are less likely to occur while using DAST as a fluorinating reagent, exo- and endo-borneol is more easily rearranged in order to yield compound $\mathbf{2}$. The fluorination of borneol using DAST led to a rearranged fluoride $\mathbf{2}$ (Scheme 3).

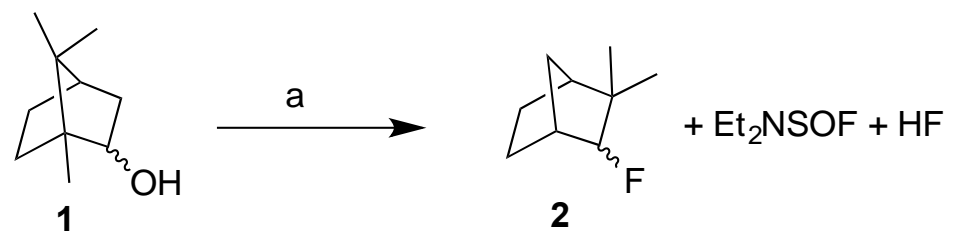

Scheme 3. Fluorination of borneol 1. Reagents/Conditions: (a) DAST. 
Camphor 3 was fluorinated by the Britton group as described in a 2014 communication through the use of a photocatalytic fluorination reaction as detailed in Scheme $4 .{ }^{18}$ Fluorination occurred at positions that were most remote from the carbonyl group.

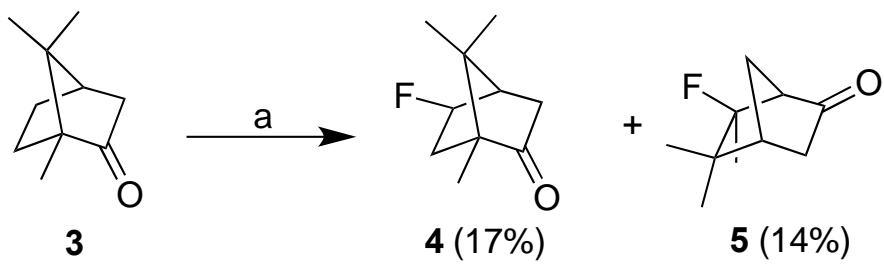

Scheme 4. Fluorination of camphor 3. Reagents/Conditions: (a) 1.5 equiv NFSI/0.1 equiv $\mathrm{NaHCO}_{3} / 0.02$ equiv TBADT/ MeCN/365 nm, $16 \mathrm{~h}$.

Myrcene, a commercially available monoterpenoid, has also been fluorinated with the goals of utilizing fluorinated terpenes in a wide variety of general cleaning and degreasing applications. ${ }^{19}$ Myrcene 6, combined with trifluorochloromethane and fluorine gas, was then passed through a sodium fluoride trap to yield fluorinated compounds $\mathbf{7}$ and $\mathbf{8}$ (Scheme 5).

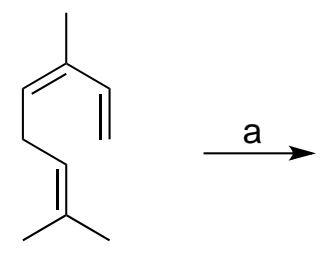

6

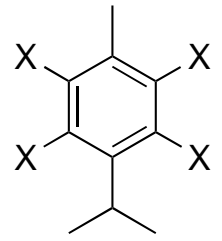

7

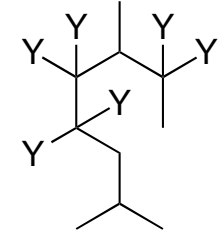

8

Scheme 5. Fluorination of myrcene 6. Reagents/Conditions: (a) $\mathrm{CFCl}_{3} / \mathrm{F}_{2} . \mathbf{7 : X}$ is hydrogen or fluorine and at least two of $X$ are fluorine. 8: $Y$ is hydrogen or fluorine and at least two of $Y$ are fluorine.

The preparation of fluorinated natural sesquiterpenoids based on the drimane system has been reported and has focused on the production of 9- $\alpha$-fluoro derivatives 9-14. ${ }^{20}$ Abad's group sought to prepare several fluorinated analogues of the drimane framework and investigate how these changes could affect their chemical properties and biological activity. Fluorinated albicanic acid $\mathbf{1 1}$ was prepared from the starting fluorodecalone 9 which underwent a Wittig methylenation to afford $\beta, \gamma$-unsaturated ester $\mathbf{1 0}$ (Scheme 6). Ester cleavage of 10 with NaSPr in DMF yielded $9 \alpha$-fluoroalbicanic acid 11. The 9-fluorinated albicanol 12 was also synthesized from fluorodecalone $\mathbf{9}$ in which the methylenated compound $\mathbf{1 0}$ was reduced with lithium aluminum hydride to provide alcohol 12. Acetylation of $9 \alpha$-fluoroalbicanol, 12, afforded $9 \alpha$-fluoroalbicanyl acetate, 13. Conversion of alcohol 12 to corresponding aldehyde 14 was performed using the Dess-Martin periodinane oxidation reagent and resulted in $9 \alpha$-fluoroalbicanal 14 (Scheme 6).

Preparation of $9 \alpha$-fluorodrimenin 18 was accomplished from fluorodecalone 9 . Preparation of diester 16 occurred through converting decalone $\mathbf{9}$ to the corresponding enol triflate 15 with potassium hexamethyldisilazane/ $\mathrm{N}$-phenyltriflamide. The triflate $\mathbf{1 5}$ was then treated with a palladium catalyst to undergo a palladium-catalyzed carbonylation thereby providing the dimethyldiester $\mathbf{1 6}$. Arrival at $9 \alpha$-fluorodrimenin 18 was accomplished through lactonization of hydroxester $\mathbf{1 7}$ using DBU and molecular sieve (Scheme 7). 


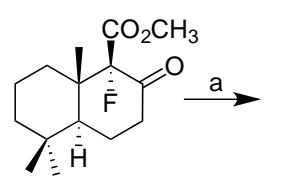

9

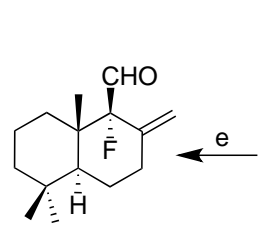

14

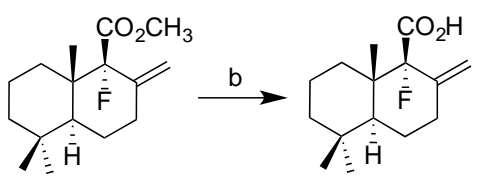

11

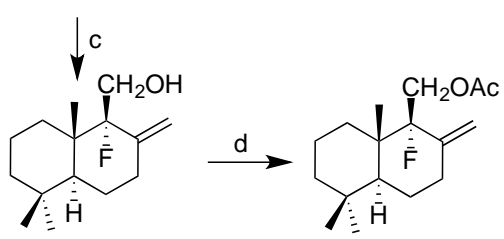

12

13

Scheme 6. Preparation of 9- $\alpha$-fluoro derivatives. Reagents/Conditions: (a) $\mathrm{Ph}_{3} \mathrm{PCH}_{3} \mathrm{Br} / \mathrm{KHMDS} /$ $\mathrm{CH}_{3} \mathrm{Ph} /$ room temp./2h; (b) NaH/PrSH$/ \mathrm{DMF} / 80^{\circ} \mathrm{C} / 2 \mathrm{~h}$; (c) $\mathrm{LiAlH}{ }_{4} \bullet 2 \mathrm{THF} / \mathrm{CH}_{3} \mathrm{Ph} /-40{ }^{\circ} \mathrm{C}$; (d) $\mathrm{Ac}_{2} \mathrm{O}$ /DMAP/Py/room temp./1.5 h; (e) DMP-py/ $\mathrm{CH}_{2} \mathrm{Cl}_{2} /$ room temp./4.5 h.

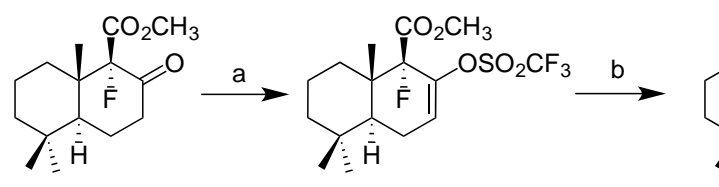

9
15

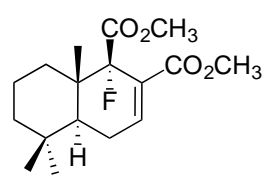

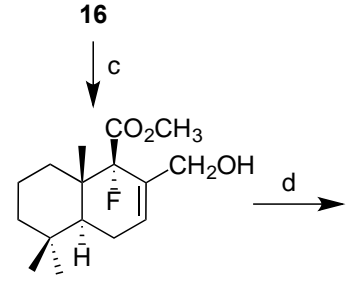

17

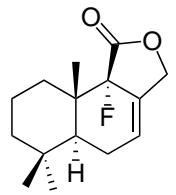

18

Scheme 7. Synthesis of 9- $\alpha$-fluorodrimenin 18. Reagents/Conditions:(a) $\mathrm{KHMDS} / \mathrm{PhNTf}_{2} / \mathrm{THF} /$ $-78^{\circ} \mathrm{C}$; (b) $\mathrm{Pd}(\mathrm{OAc})_{2} / \mathrm{PPh}_{3} / \mathrm{Pr}_{2} \mathrm{Net} / \mathrm{CO} / \mathrm{CH}_{3} \mathrm{OH} / \mathrm{DMF} / 65^{\circ} \mathrm{C}$; (c) DIBAL-H/THF $/ \mathrm{C}_{6} \mathrm{H}_{12} / 78^{\circ} \mathrm{C}$;

(d) $\mathrm{DBU} / 3 \AA \mathrm{AS} / \mathrm{C}_{6} \mathrm{H}_{6} /$ room temp.

More complex terpenoids and their derivatives have undergone selective fluorination, including taxol, forskolin, tocopherol, artemisinin, and nerolidol and the potential benefits are self-explanatory, especially when applied to anticancer compounds such as taxol and antimalarials such as the artemisinins. Due to the wide use of fluorinated aromatic compounds in pharmaceuticals, agrochemicals, materials, and as tracers for positron emission tomography (PET), the Ritter group investigated new ways to form carbon-fluorine bonds. The methods were developed while exploring the specific application of silver catalysts. In turn, the mild conditions resulted in good functional group tolerance and wide substrate scope. ${ }^{21}$ Biologically active molecules, including natural products, have been fluorinated using Ritter's catalysis technology successfully and in good yields. The use of the silver catalyst with the electrophilic fluorination can occur with aromatic rings in the presence of other functional groups, such as alcohols, dienones, vinyl ethers, esters, and oxetanes, proving this to be a beneficial fluorinating option for. Taxol $\mathbf{1 9}$ has been selectively fluorinated on the aromatic ring using the electrophilic fluorinating reagent, F-TEDA-PF 6 in the presence of a silver catalyst (Scheme 8). 


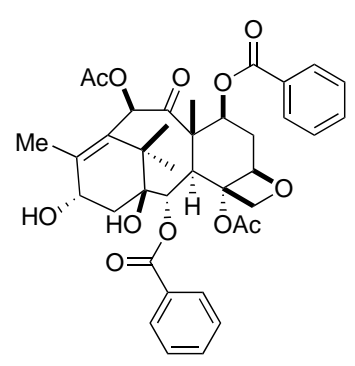

19

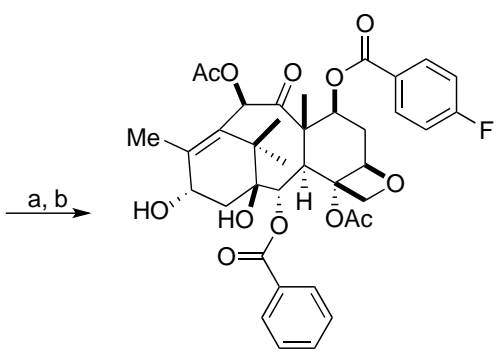

20

Scheme 8. Fluorination of taxol 19. Reagents/Conditions: (a) 5.0 mol\% $\mathrm{Ag}_{2} \mathrm{O} / 1.0$ equiv NaOTf/ 2.0 equiv $\mathrm{NaHCO}_{3}$; (b) 1.5 equiv F-TEDA-PF $6 /$ acetone $/ 65^{\circ} \mathrm{C}$.

The Ritter group also selectively fluorinated $\delta$-tocopherol, Vitamin E $\mathbf{2 1}$ at the hydroxyl position with FTEDA-PF 6 to afford product 22 (Scheme 9). ${ }^{22}$

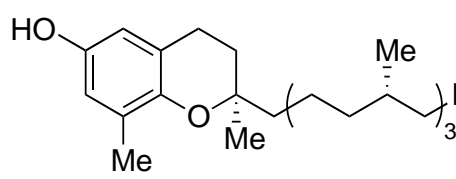

21

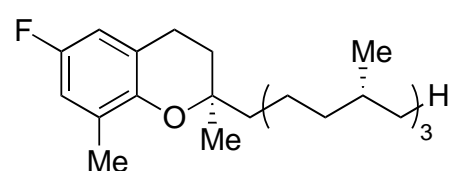

22

Scheme 9. Fluorination of $\delta$-tocopherol 21. Reagents/Conditions: (a) $\mathrm{Tf}_{2} \mathrm{O} / \mathrm{NET}_{3}$; (b) $\mathrm{LiCl} / 5 \mathrm{~mol} \%$ $\mathrm{Pd}\left(\mathrm{PPh}_{3}\right)_{4} /\left({ }^{\mathrm{n} B u_{3} \mathrm{Sn}}\right)_{2} ;$ (c) 1.2 equiv F-TEDA-PF $6 / 2.0$ equiv AgOTf/acetone $/ 23^{\circ} \mathrm{C} / 20 \mathrm{~min}$.

Further investigations by Ritter revealed the use of PhenoFluor ${ }^{\circledR}$ as a late-stage deoxyfluorination reagent of alcohols in which both terpenoids $(E)$-nerolidol $\mathbf{2 3}$ and artemisinin $\mathbf{2 5}$ were both selectively fluorinated to give products 24 and 26 respectively (Scheme 10). ${ }^{23}$

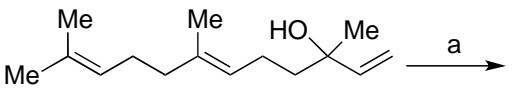

23

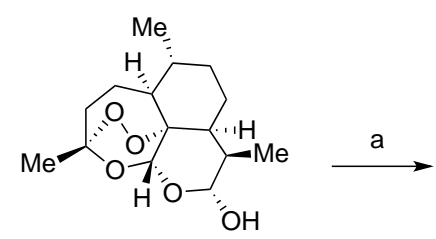

25

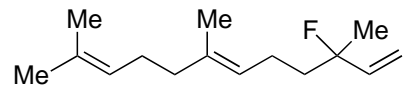

24

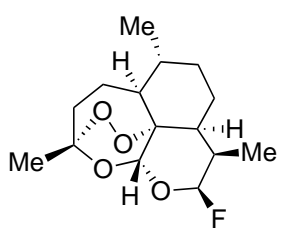

26

Scheme 10. Fluorination of $(E)$-nerolidol 23 and artemisinin 25. Reagents/Conditions: (a) Phenofluor ${ }^{\mathrm{TM}} / 2.0$ equiv. EtNiPr2/ 2.0 equiv. KF/ 2-20h.

The fluorination of natural sclareolide $\mathbf{2 7}$ was investigated by Britton's group as shown in Scheme 11. One may note that the fluorination system was highly efficient and the (2S)-2-fluorosclareolide $\mathbf{2 8}$ was produced as the major product while the 1 -fluorosclareolide 29 was the minor product (Scheme 11). ${ }^{18}$ 


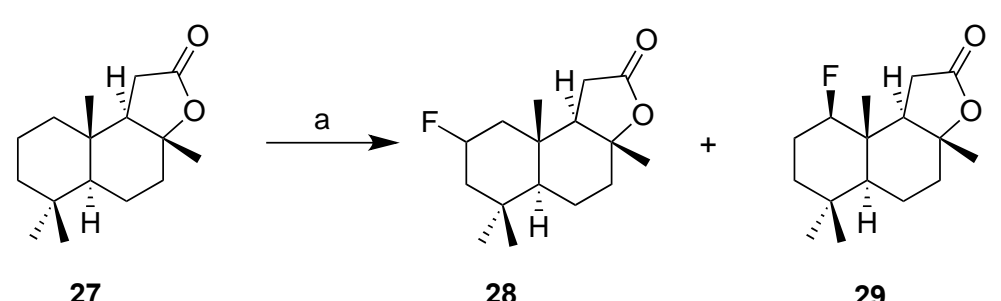

Scheme 11. Fluorination of sclareolide 27. Reagents/conditions: (a) 1.5 equiv NFSI/0.02 equiv TBADT/ $\lambda=365$ $\mathrm{nm} / \mathrm{NaHCO}_{3} / \mathrm{MeCN}$.

Sclareolide was also fluorinated by the Groves group using a manganese porphyrin-catalyzed selective C-H fluorination with silver fluoride to yield title tricyclic fluorinated lactone $\mathbf{3 0}$ (Scheme 12). ${ }^{24}$

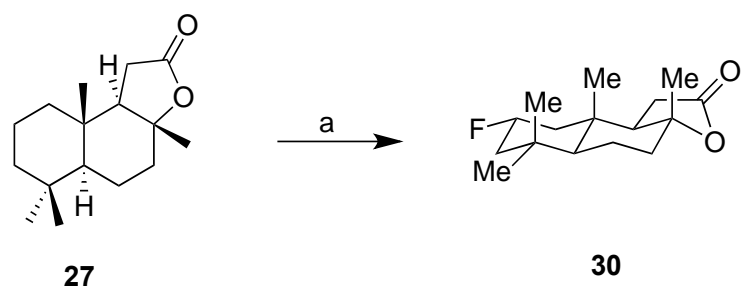

Scheme 12. Fluorination of sclareolide 27. Reagents/conditions: (a) $\mathrm{Mn}(\mathrm{TMP}) \mathrm{Cl}$ (8 mol\%)/AgF (3 eq.)/TBAF (0.3 eq.)/PhIO (10 eq.).

Forskolin 31, an adenylyl cyclase activator, was fluorinated utilizing the reaction of its lithium enolate which was generated by lithium hexamethyldisilazide. The enolate was reacted with acetyl hypofluorite to produce 12-fluoroforskolin 32 as a single diasteriomer (Scheme 13). ${ }^{25}$

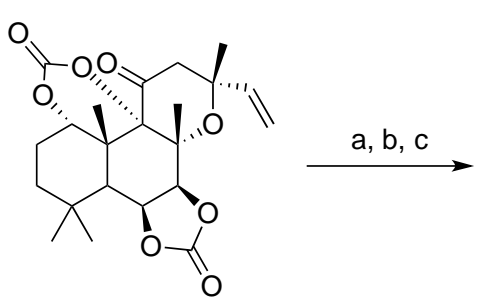

31

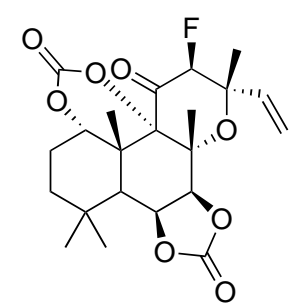

32

Scheme 13. Fluorination of forskolin 31. Reagents/Conditions: (a) LiHMDS/THF; (b) AcOF/ $\mathrm{CFCL}_{3} / \mathrm{AcOH}^{-6}-65^{\circ} \mathrm{C}$; (c) $\mathrm{NaHCO}_{3} / \mathrm{THF} / \mathrm{H}_{2} \mathrm{O}$.

\section{Lipid Natural Products}

\subsection{Aliphatic natural products}

One of the most important subgroups of aliphatic natural products are the semiochemicals. These compounds facilitate communication between many species of organisms and are vastly different amongst themselves in structure but are similar in their functionality, typically alcohols and ethers. With semiochemicals embodying 
many of the aliphatic compounds with the greatest biological importance, they are widely studied due to the biological responses they stimulate. Whenever metabolically permissible, semiochemicals can be released on purpose by the organism on an 'as needed' basis so fluorinating these compounds can produce effects on the activity and can therefore cause changes in the response of the individuals especially insects. ${ }^{26}$ Bombykol 33 is a female sex pheromone of the silkworm moth Bombyx mori whereby an understanding of its pheromone biology and chemistry has been widely explored. ${ }^{26}$ The Svatos group monofluorinated bombykol at two separate positions, at C6 and C16. Bombykol was also difluorinated at C6. The synthesis of both mono and difluoro derivatives of bombykol 34, 36 respectively is shown in Scheme 14.

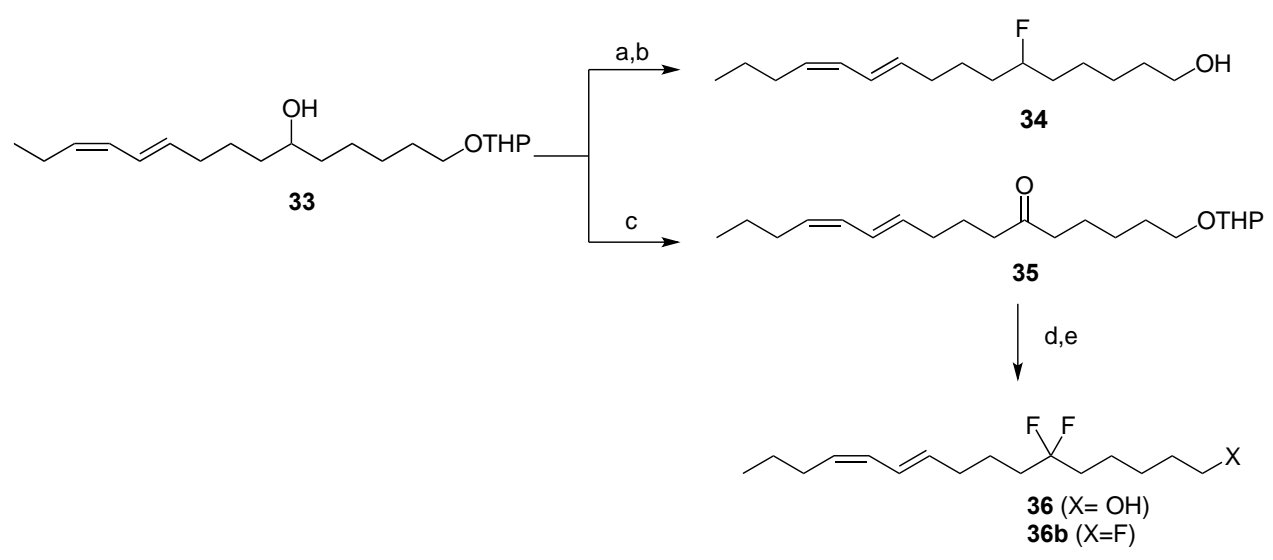

Scheme 14. Fluorination of bombykol 33. Reagents/Conditions: (a) DAST; (b) PTSA; (c) PCC; (d) DAST; (e) PTSA.

Alcohol 33 was synthesized from $(E)$-iodohexan-6-ol followed fluorination using DAST. Cleavage the THP group with $p$-toluenesulfonic acid, yielded title alcohol 34. The oxidation of alcohol 33 with PCC yields ketone 35, which then upon fluorination with DAST followed by deprotection with PTSA, the target compound 36 is obtained. Unfortunately, similar fluorination occurred on the terminal alcohol as well to form 36b. 16fluorobombykol $\mathbf{3 8}$ was synthesized similarly as shown in Scheme 15.

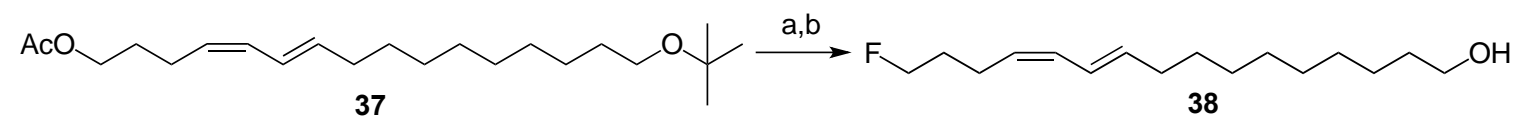

Scheme 15. Synthesis of 16-fluoro derivative 38. Reagents/Conditions: (a) MeONa; (b) DAST/ $\mathrm{Ac}_{2} \mathrm{O} / \mathrm{FeCl}_{3}$ /MeONa.

Frontalin 39, a bioactive compound and aggregation pheromone of the Scolytidae insect family, plays a significant role in chemical communication between insects. Replacement of the hydrogen atoms with fluorine atoms in pheromones can cause a variety of effects on an insect's response, thereby altering their activity. Moreover, replacing the hydrogens with fluorine is advantageous in the fact that a large change in electronic distribution occurs without a great steric difference. Along with fluorinated analogues increasing bioactivity, these compounds can be used as tracers for metabolic pathways. ${ }^{27}$ 


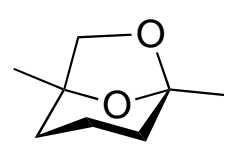

39

The synthesis of trifluorofrontalin $\mathbf{4 7}$ began with enantiopure sulfoxide $\left(R_{\mathrm{s}}\right)-\mathbf{4 0}$, which was made following the Anderson-modified procedure using 4-pentenylmagnesium bromide and (-)-(1R)-menthyl (S)-toluene-4sulfinate (Scheme 16). Treatment of the pentenyl sulfoxide $\mathbf{4 0}$ with LDA and ethyl trifluoroacetate resulted in acylation to produce ketosulfoxide $\mathbf{4 1}$. Methylene insertion with diazomethane across the carbonyl group in $\mathbf{4 1}$ afforded a diastereomeric mixture of oxiranes $\mathbf{4 2}$. The resulting mixture of oxiranes $\mathbf{4 2}$ is then subjected to electrophilic ring opening via aqueous perchloric acid, providing diol 43. In order to produce the bicyclic core of the frontalin, a Wacker oxidative process was employed on the terminal $\mathrm{C}=\mathrm{C}$ bond of diol $\mathbf{4 3}$ to afford ketodiol 44. Intramolecular ketalization of the ketodiol intermediate $\mathbf{4 4}$ subsequently occurred producing ketalsulfoxide 45. Compound $\mathbf{4 7}$ was obtained through deoxygenation of $\mathbf{4 5}$ to sulfide $\mathbf{4 6}$ and hydrogenolytic removal of the thiotolyl group led to target compound $\mathbf{4 7}$ (Scheme 16).
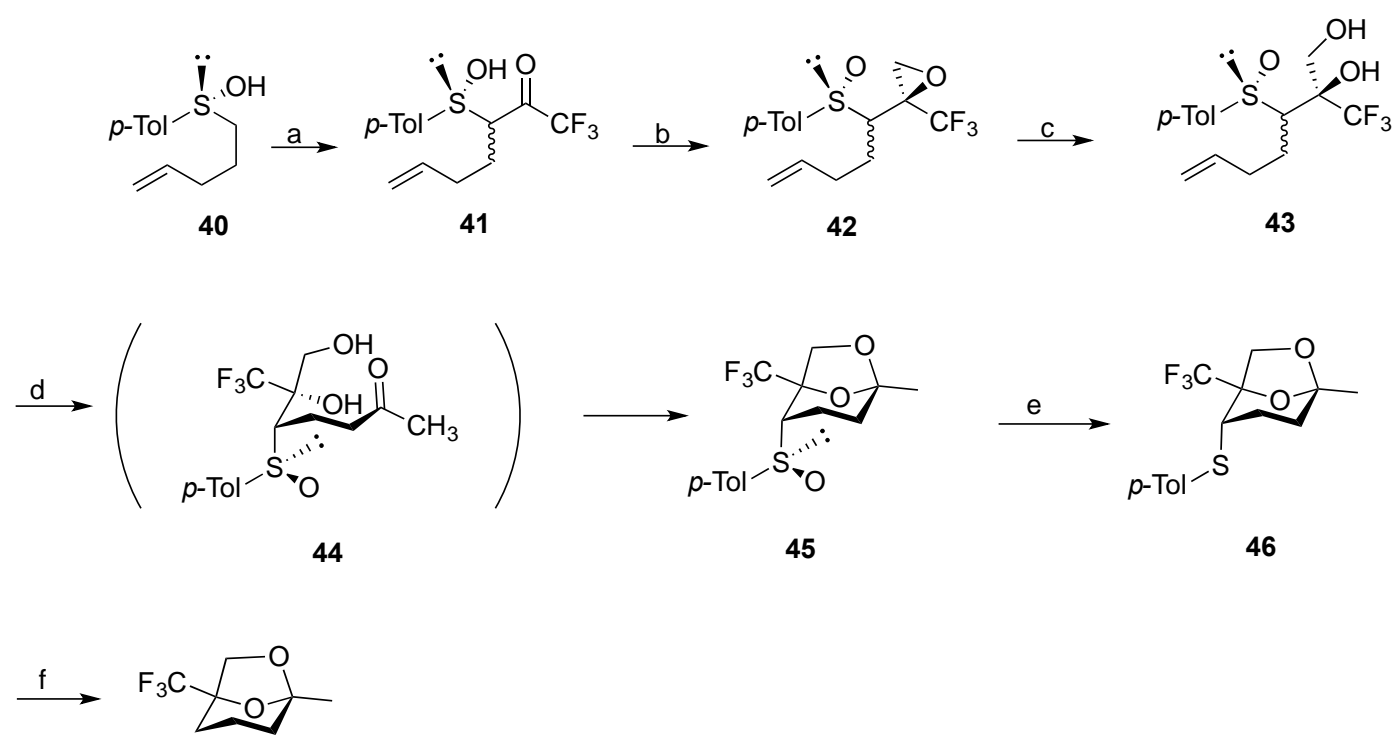

47

Scheme 16. Synthesis of trifluorofrontalin 47. Reagents/Conditions: (a) LDA/THF/CF $3 \mathrm{COOEt}_{\text {; }}$ (b) $\mathrm{CH}_{2} \mathrm{~N}_{2} / \mathrm{MeOH}$ / $-40^{\circ} \mathrm{C}$; (c) $\mathrm{HClO}_{4} / \mathrm{THF} / \mathrm{H}_{2} \mathrm{O} / 40^{\circ} \mathrm{C} / 7 \mathrm{~d}$; (d) $\mathrm{CuCl}_{2} / \mathrm{PdCl}_{2} / \mathrm{DME}$; (e) Nal/TFAA/ acetone; (f) Raney-Ni/( $\left.\mathrm{HOCH}_{2}\right)_{2}$.

Monofluorofrontalin 54 was synthesized from fluoroketosulfoxide $\mathbf{4 8}$ (Scheme 17). Alkylation of 48 with $3-$ butenyl bromide (LDA/HMPA) gave fluoropentenyl sulfoxide $\mathbf{4 9}$. Treatment of $\mathbf{4 9}$ with diazomethane affords oxirane $\mathbf{5 0}$ which was hydrolyzed to diol $\mathbf{5 1}$ by catalysis with perchloric acid $\left(\mathrm{THF} / \mathrm{H}_{2} \mathrm{O}\right)$. Further treatment of $\mathbf{5 1}$ with $\mathrm{PdCl} / \mathrm{CuCl}_{2} / \mathrm{O}_{2}$ provided bicyclic sulfoxide, 52. Deoxygenation of $\mathbf{5 2}$ (Nal/TFA) provided sulfide $\mathbf{5 3}$ which was then reductively desulfurized with Raney nickel (ethylene glycol/110 ${ }^{\circ} \mathrm{C}$ ) to give the title compound, 54 .

The fluorinated analogues of the C12 fatty acid, lauric acid was prepared recently by the Yu group in 2013. Starting materials 12-Hydroxydodecanoic acid and 12-carboxydodecanal was mono and di-fluorinated respectively at the $\mathrm{C} 12$ position with Deoxofluor ${ }^{\oplus}$ yielding 12 -fluorododecanoic acid $\mathbf{5 8}$, and 12,12 difluorododecanoic acid 61 (Scheme 18). ${ }^{28}$ 

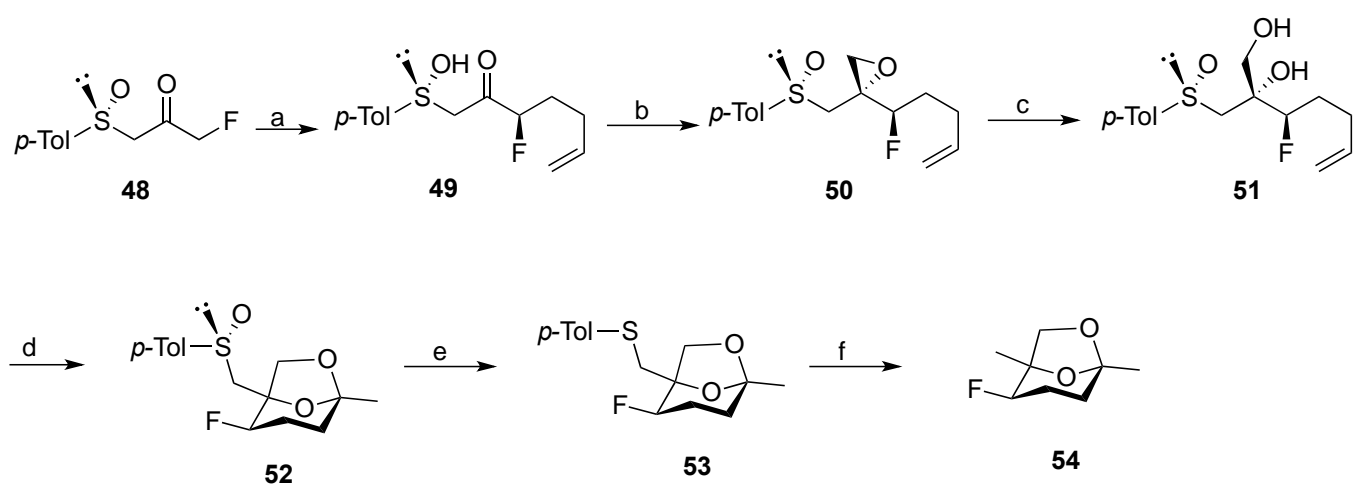

Scheme 17. Synthesis of monofluorofrontalin 54. Reagents/Conditions: (a) LDA/ $n-\mathrm{C}_{4} \mathrm{H}_{7} \mathrm{Br} / \mathrm{HMPA} / \mathrm{THF} /-60{ }^{\circ} \mathrm{C}$ /FC; (b) $\mathrm{CH}_{2} \mathrm{~N}_{2} / \mathrm{MeOH} / 0{ }^{\circ} \mathrm{C}$; (c) $\mathrm{HClO}_{4} / \mathrm{THF} / \mathrm{H}_{2} \mathrm{O} / 40{ }^{\circ} \mathrm{C}$; (d) $\mathrm{CuCl}_{2} / \mathrm{PdCl}_{2} / \mathrm{O}_{2} /$ diglyme, rt; (e) Nal/ TFAA/ acetone/$20{ }^{\circ} \mathrm{C}$; (f) Raney-Ni/(HOCH$)_{2} / 110{ }^{\circ} \mathrm{C}$.

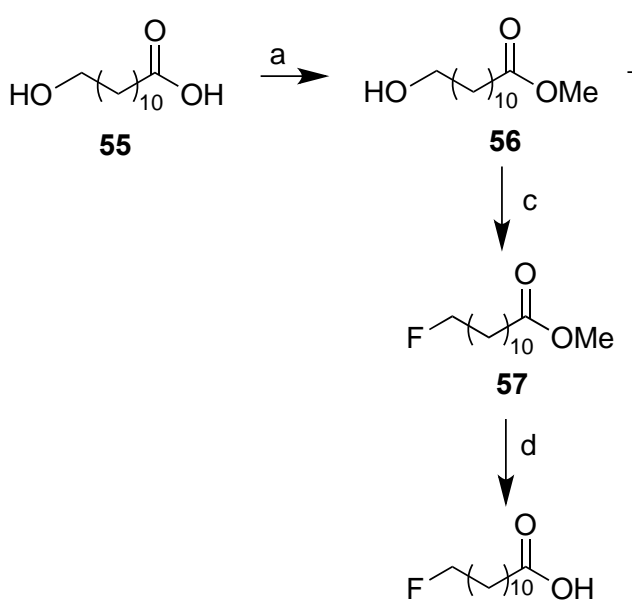

58

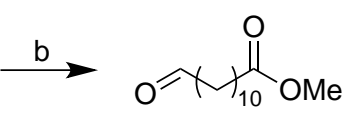

59

$\downarrow c$<smiles>COC(=O)CCCC(F)F</smiles><smiles>CC(C)CCCC(=O)O</smiles>

61

Scheme 18. Preparation of lauric acid analogues 58 and 61. Reagents/Conditions: (a) $\mathrm{H}^{+} / \mathrm{MeOH} / \mathrm{RT} / 12 \mathrm{~h}$; (b) $\mathrm{PCC} / \mathrm{CH}_{2} \mathrm{Cl}_{2} / \mathrm{rt} / 2 \mathrm{~h}$; (c) Deoxo-Fluor ${ }^{\oplus} \mathrm{CH}_{2} \mathrm{Cl}_{2} / 0{ }^{\circ} \mathrm{C}$ to rt/30 min; (d) $\mathrm{LiOH} \bullet \mathrm{H}_{2} \mathrm{O} / \mathrm{THF} / \mathrm{MeOH} / \mathrm{H}_{2} \mathrm{O} / \mathrm{RT} / 4 \mathrm{~h}$.

\subsection{Acetogenins}

Annonacin 62 is a neurotoxic natural product which was isolated from the fruit pulp of the Caribbean soursop and the North American pawpaw, both species of the family Annonacea. In general, annonacin is a member of the annonaceous acetogenin family of natural products whereby the compounds possess lipid-like structures that may bear single or multiple THF rings as well as a terminal butenolide ring. The compound was found to be toxic to rat cortical neurons and is suspected to cause atypical Parkinson's syndrome in populations in which there is a high consumption rate of the fruit. Naturally-derived annonnacin is also antiangiogenic in the rat aortic ring assay at $30 \mu \mathrm{M}$. Preliminary results suggest that an excess of DAST in dichloromethane is useful for tetrafluorination of 62 at each of its hydroxyl positions as indicated by ${ }^{1} \mathrm{H} 400 \mathrm{MHz}$ spectroanalysis of the reaction product 63 (Scheme 19). ${ }^{29}$ While one may anticipate inversion of stereochemistry at each of the fluorination sites, it has yet to be determined. 


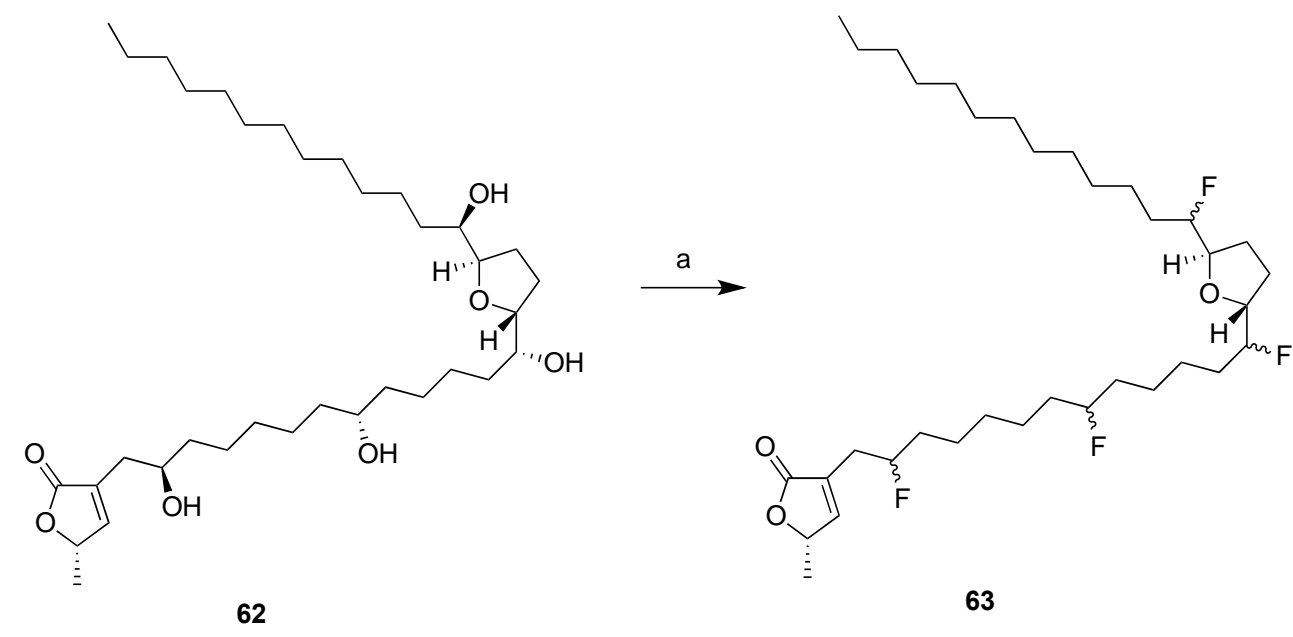

Scheme 19. Tetrafluorination of annonacin 62. Reagents/Conditions: Excess DAST/MeOH.

\subsection{Steroids}

Fluorinated steroids are active components of a number of important pharmaceuticals. ${ }^{30}$ Studying the fluorination of naturally occurring steroids can lead to new innovations in hormone medicine as well as discovering new methods of fluorinating these polycyclic lipids. Estrone 64 , one of several naturally occurring estrogens, is a hormone secreted from the ovaries. This well-known steroid has been fluorinated in multiple accounts by Ritter's group utilizing a silver catalyst. ${ }^{21,22}$ In their first account Ritter's group utilized a similar approach that they used to fluorinate $\delta$-tocopherol (Scheme 9) in order to selectively fluorinate estrone 64 (Scheme 20).

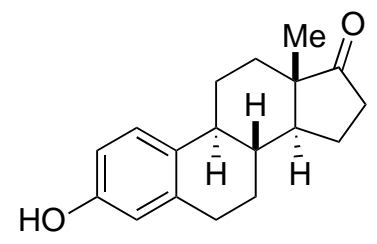

64

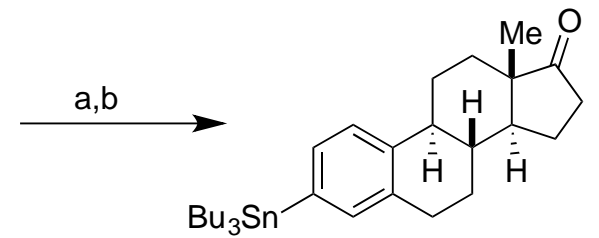

65

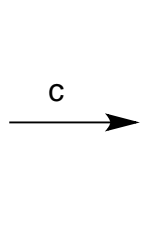

$\overbrace{66}$

Scheme 20. Fluorination of estrone 64. Reagents/Conditions: (a) $\mathrm{Tf}_{2} \mathrm{O} / \mathrm{Et} \mathrm{t}_{3} \mathrm{~N}$; (b) $\mathrm{LiCl} / \mathrm{Pd}\left(\mathrm{PPh}_{3}\right)_{4} /\left(\mathrm{Bu}_{3} \mathrm{Sn}\right)_{2}$; (c) AgOTrif/F-TEDA-PF 6 .

The conversion of estrone $\mathbf{6 4}$ to 3-fluoro-3-deoxyestrone $\mathbf{6 6}$ first involves the triflation of estrone followed by a palladium-mediated stannylation giving the intermediate stannylated steroid $\mathbf{6 5}$. Fluorodestannylation of the aromatic ring leading to the title compound employed the electrophilic fluorinating agent F-TEDA-BF 4 or FTEDA-PF 6 in the presence of silver triflate (Scheme 20). ${ }^{22}$ One year later, Ritter's group performed another late stage fluorination on estrone (Scheme 21). ${ }^{21}$ 
<smiles>C[C@]12CC[C@H]3c4ccc(O)cc4CC[C@H]3[C@H]1CCC2=O</smiles>

64

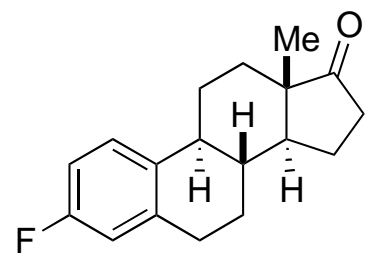

66

Scheme 21. Fluorination of estrone 64. Reagents/Conditions: (a) 5.0 mol\% $\mathrm{Ag}_{2} \mathrm{O} / 2.0$ equiv $\mathrm{NaHCO}_{3} / 1.0$ equiv NaOTf/1.5 equiv F-TEDA-PF $6 /$ acetone $/ 65^{\circ} \mathrm{C}$.

Estradiol 67 another naturally occurring estrogen, has also been fluorinated in multiple accounts, in which Selectfluor ${ }^{\circledR}$ is utilized as an electrophilic fluorinating reagent (Scheme 22). ${ }^{31,32}$

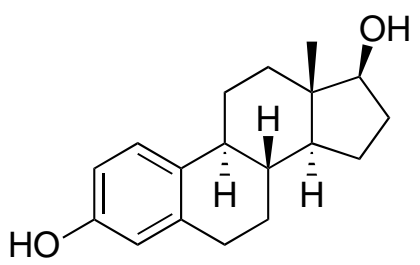

67

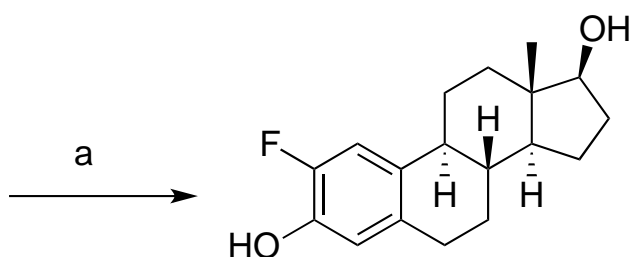

68

Scheme 22. Fluorination of estradiol 67. Reagents/Conditions: (a) Selectfluor ${ }^{\circledR} / \mathrm{bmimBF}_{4} / \mathrm{CH}_{3} \mathrm{OH} / 20^{\circ} \mathrm{C}$.

Allo-Pregnanedione 69 an endogenous progestogen, has been fluorinated by the MacMillan group utilizing an enantioselective organocatalytic $\alpha$-fluorination reaction to give product 70. ${ }^{33}$ After successfully investigating multiple cyclohexanone compounds, the MacMillan group utilized their findings to fluorinate a more complex cycloketone as seen in Scheme 23. Depending on which catalyst is used the selectivity of fluorination can be manipulated.

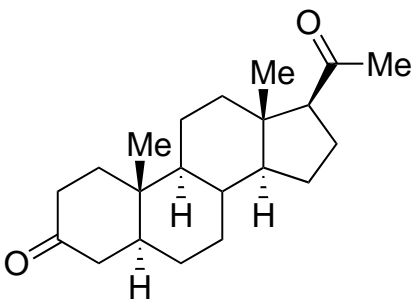

69

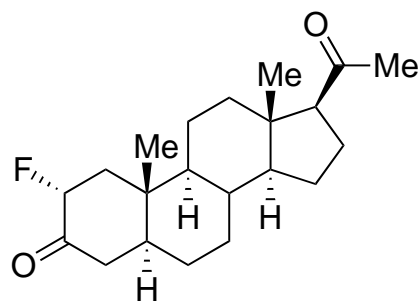

70

Scheme 23. Fluorination of allo-pregnanedione 69. Reagents/Conditions: (a) NFSI/ $\mathrm{Na}_{2} \mathrm{CO}_{3} / \mathrm{THF} / \mathrm{DCM}$.

The Ritter group selectively fluorinated steroids, testosterone $\mathbf{7 1}$ and epi-androsterone $\mathbf{7 3}$ as reported in 2013 and employed a late-stage deoxofluorination of alcohols with Phenofluor ${ }^{\mathrm{TM}}$ as previously mentioned earlier. ${ }^{23}$ Both compounds underwent replacement of the alcohol group with a fluorine atom in which inversion of stereochemistry occurred to provide $\mathbf{7 2}$ and $\mathbf{7 4}$ (Schemes 24, 25). 


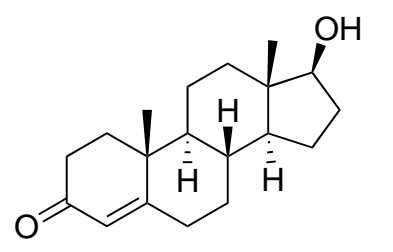

71

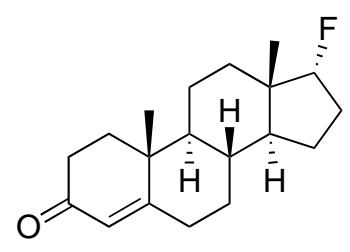

72

Scheme 24. Fluorination of testerone 71. Reagents/Conditions: (a) Phenofluor ${ }^{\mathrm{TM}} / 2.0$ equiv EtN $\mathrm{Pr}_{2} / 2.0$ equiv $\mathrm{KF} / 2-20 \mathrm{~h}$.

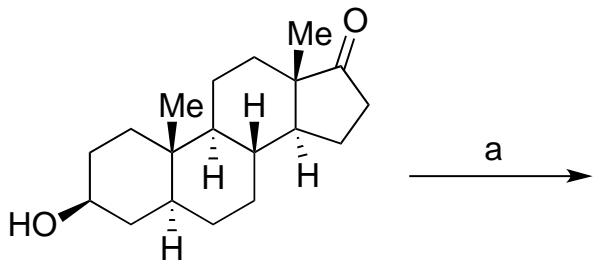

73

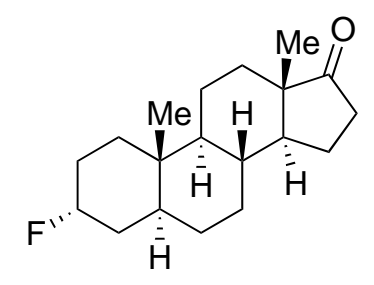

74

Scheme 25. Fluorination of epi-androsterone 73. Reagents/Conditions: (a) Phenofluor ${ }^{\mathrm{TM}} / 2.0$ equiv EtN $\mathrm{Pr}_{2} / 2.0$ equiv KF/2-20 h.

In the concise synthesis of 6- $\alpha$-fluoroursodeoxychlolic acid 79 (Scheme 26), a Novartis process group used Selectfluor ${ }^{\circledast}$ to fluorinate the enol ether of $\mathbf{7 7}$ which resulted in total desilylation and provided the $\alpha-$ fluoroketone 78 (Scheme 26). ${ }^{34}$ Subsequent steps which gave a key intermediate included equilibration to the $6 \alpha$-fluoroketone with sodium methoxide/methanol, formation of the methyl ester using methanol/chlorotrimethyl silane, acetylation of the 3-hydroxyl group ( $\mathrm{Ac}_{2} \mathrm{O} / \mathrm{DMAP}$ ). 6a-Fluoroketone 78 was then reduced with $\mathrm{H}_{2}$ /platinum oxide followed by mesylation (mesyl chloride/DMAP) and mesyl displacement ( $\mathrm{KO}_{2}$ /DMSO) giving inversion at C-7 and thus the title compound 79.

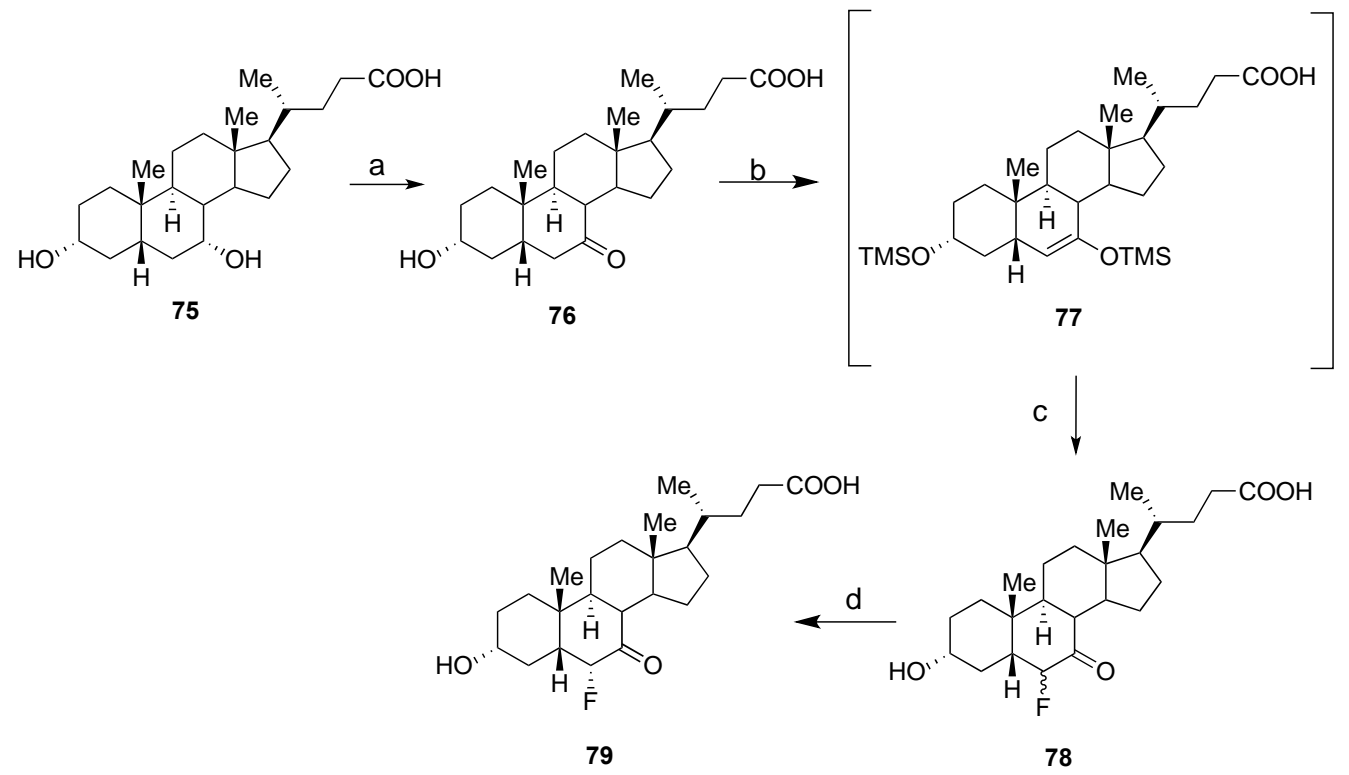

Scheme 26. Fluorination of chenodeoxycholic acid 75. Reagents/Conditions: (a) $\mathrm{NaOCl} / \mathrm{Bu}_{4} \mathrm{~N}^{+} \mathrm{Br}^{-} / \mathrm{NaBr}$; (b) TMSCl/ Nal; (c) Selectfluor ; (d) NaOMe/MeOH/TMSCl/MeOH/Ac $2 \mathrm{O} / \mathrm{DMAP}$. 
The Novartis synthesis was in contrast to the previous synthesis of $\mathbf{7 9}$ by an Italian group whereby DAST in dichloromethane was used to fluorinate followed by desilylation of TBDMS-protected hydroxyketone $\mathbf{8 0}$ (Scheme 27). ${ }^{35}$ The resulting $\alpha$-fluoroketone 81 was saponified with $\mathrm{KOH}$ in methanol which afforded ketocarboxylic acid 79. The 6-ketogroup of $\mathbf{7 9}$ was then reduced with sodium borohydride in methanol to give title compound 82.

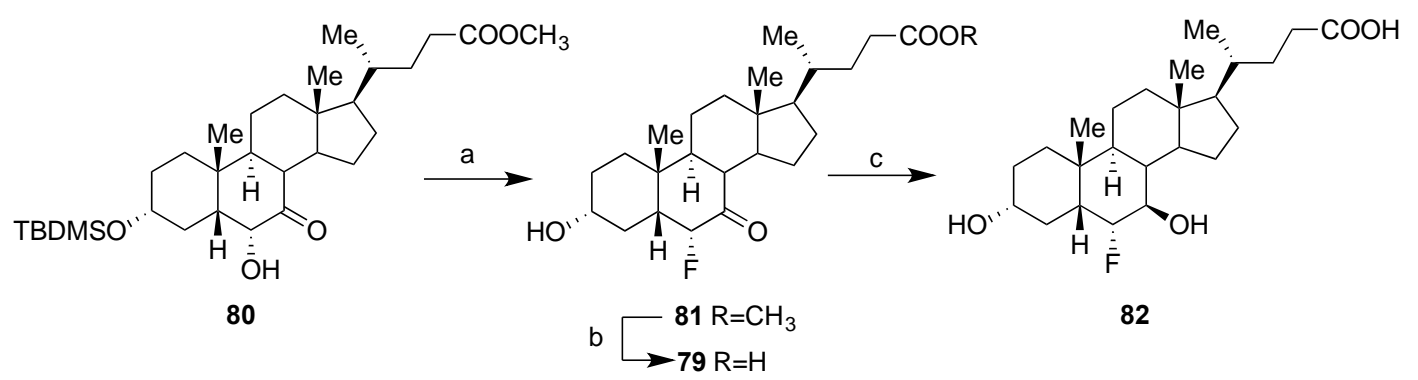

Scheme 27. Fluorination of chenodeoxycholic acid 75. Reagents/Conditions: (a) DAST/DCM; (b) KOH/MeOH; (c) $\mathrm{NaBH}_{4} / \mathrm{MeOH}$.

\section{Polyketides}

Structurally complex as well as highly bioactive, the polyketide family has become a great area of research within the biochemical community. This class of secondary metabolites, produced by living organisms, are structurally diverse from one another and are potent pharmaceuticals. Avermectin $B_{1 A} \mathbf{8 3}$ is a representative polyketide that has been widely used for the treatment of parasites in animals, plants, and humans and is known for its high biological activity and complex structure. Based on this knowledge, new derivatives that even further enhance these properties have been developed. The fluorination technique of naturally occurring Avermectin $B_{1 A}$ was carried out by the Meinke group. ${ }^{36}$ As part of their initiative to determine new avermectin derivatives with enhanced biological activity, the Meinke group explored the option of preparing a gem-difluoro derivative of the parent natural product. Starting compound $\mathbf{1 0 0}$ was fluorinated at position 23 across the alkene, using fluorinating reagent, DAST, noted in Scheme 28. Title compound $\mathbf{8 3}$ was successfully fluorinated and analyzed in a pentamethylenetetrazole (PTZ) mouse epilepsy model. The results portrayed a three-fold increase for the difluoro derivative in protecting against PTZ induced seizures compared to ivermectin, a non-fluorinated avermectin derivative. Although the fluorination derivative did not display greater activity than known drug, diazepam, compound $\mathbf{8 4}$ lacks the sedative effects of diazepam, a notable positive feature.

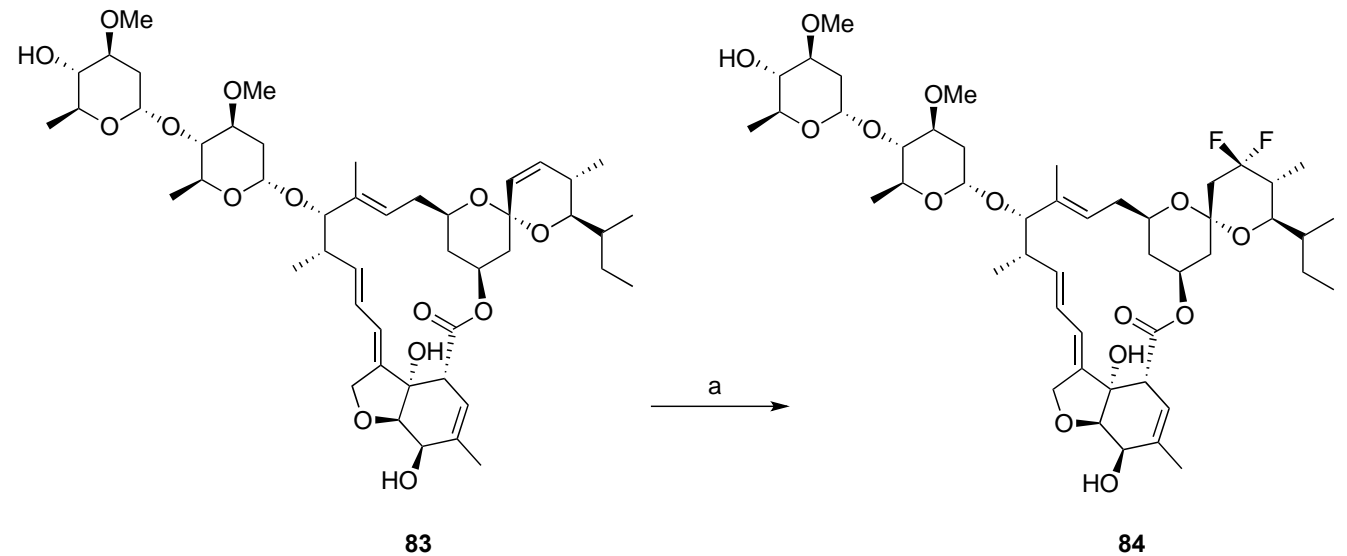


Scheme 28. Fluorination of avermectin 83. Reagents/Conditions: (a) excess DAST.

The natural polyketide antibiotic, rifamycin S 85 has been fluorinated on the aromatic ring using the electrophilic fluorinating reagent, F-TEDA-PF 6 , in the presence of a silver catalyst (Scheme 29). The formation of the carbon-fluorine bond in $\mathbf{8 6}$ was performed in the last synthetic step, where the fluorination occurs with exclusive regioselectivity. ${ }^{22}$

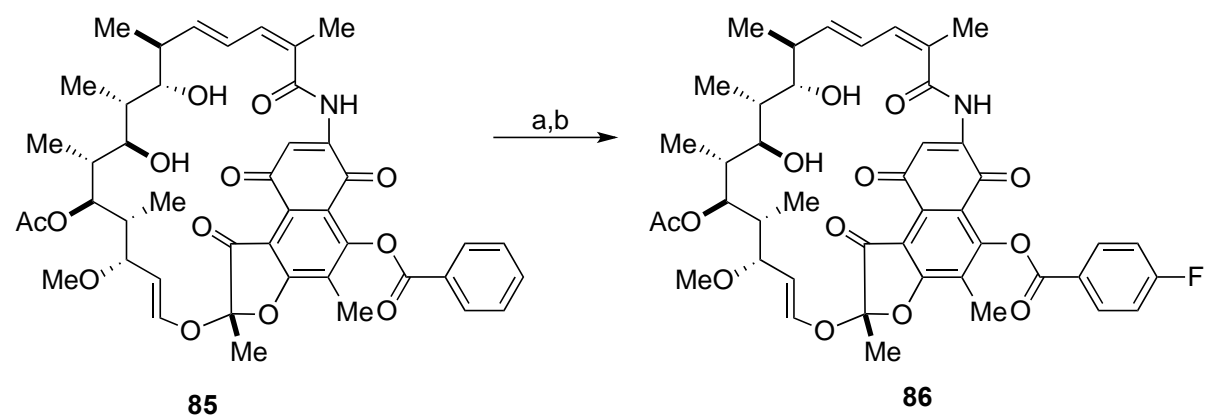

Scheme 29. Fluorination of rifamycin S 85. Reagents/Conditions: (a) 20 mol\% AgOTf/2.0 equiv NaOTf/5.0 equiv $\mathrm{MeOH}$; (b) 1.5 equiv F-TEDA-PF $6 /$ acetone $/ 65^{\circ} \mathrm{C}$.

Again, the Ritter group investigated the fluorination of natural products to generate optimized derivatives that can be optimized with increased pharmacological profiles. ${ }^{23}$ Specifically, late stage fluorination is being examined, where oligomycin A $\mathbf{8 7}$ was fluorinated with commercially available PhenoFluor ${ }^{\mathrm{TM}}$, a deoxyfluorinating reagent that can be utilized on a multi-functional group level. The selective deoxyfluorination of polyketide oligomycin A is shown in Scheme 30, and is an example of a chemoselective introduction of fluorine into a complex molecule thereby yielding secondary fluoride $\mathbf{8 8}$.

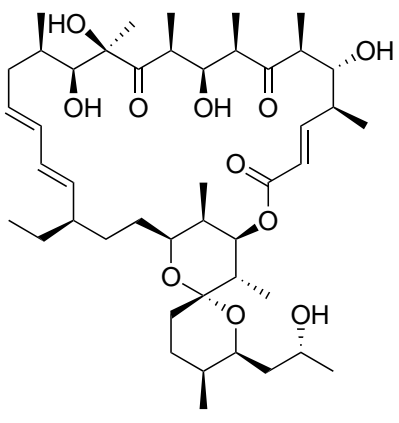

87

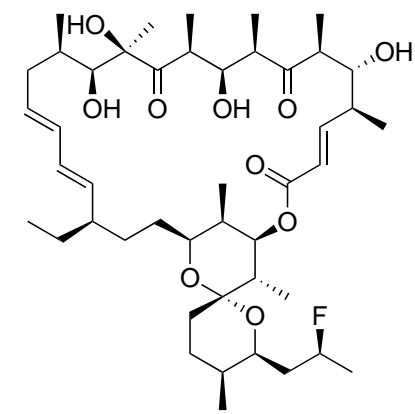

88

Scheme 30. Fluorination of oligomycin 87. Reagents/Conditions: (a) Phenofluor ${ }^{\mathrm{TM}} / 2.0$ equiv. EtN'Pr $2 / 2-20$ h.

\section{Carbohydrates}

\subsection{Hexopyranosides}


Being central to many fundamental biological processes, carbohydrates are an important class of compounds to investigate in terms of fluorinated analogues. Selectively-fluorinated carbohydrates may be used as tools to elucidate glycoprocessing mechanisms and have been useful in medicinal chemistry, pharmacology and biochemistry. Research groups have looked into decreasing polarity of sugars through replacing $\mathrm{CHOH}$ groups with $\mathrm{CF}_{2}$ groups, therefore creating a more hydrophobic environment. ${ }^{37}$ Linclau's group sought to synthesize mono- and difluorinated 2,3-deoxy-D-glucopyranoses. Starting epoxide 89 was obtained from D-glucal. As shown in Scheme 31, 89 underwent a regioselective epoxide opening with potassium hydrogen bifluoride to yield fluoroalcohol $\mathbf{9 0}$. Fluoroalcohol $\mathbf{9 0}$ was then treated with DAST to afford trans 1,2-difluoriide 91 . Benzyl deprotection of 91 was accomplished with $\mathrm{BCl}_{3}$ followed by quenching with water to yield 2,3-dideoxy-2,3difluoro-D-glucose 92 (Scheme 31).

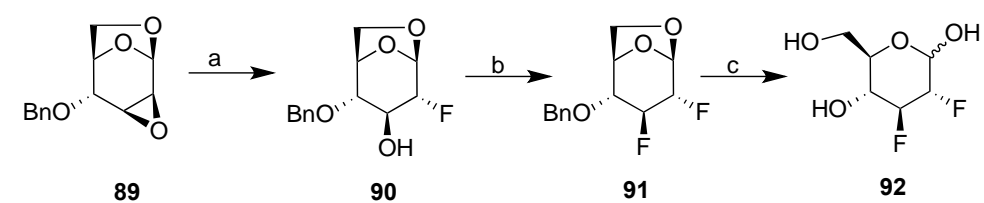

Scheme 31. Synthesis of 2,3-dideoxy-2,3-difluoro-D-glucose 92. Reagents/Conditions: (a) $\mathrm{KHF}_{2} /\left(\mathrm{CH}_{2} \mathrm{OH}\right)_{2} / \mathrm{reflux}$; (b) DAST/toluene/reflux; (c) $\mathrm{BCl}_{3} / \mathrm{H}_{2} \mathrm{O}$.

The synthesis of 2,3-dideoxy-3-fluoro-D-glucose 96 is outlined in Scheme 32. Again a deoxofluorination of benzyloxyalcohol $\mathbf{9 3}$ with DAST was utilized to provide benzyloxyfluoride $\mathbf{9 4}$. The bicyclic ether moiety of $\mathbf{9 4}$ was then hydrolyzed with sulfuric acid to yield diol $\mathbf{9 5}$. Hydrogenolysis of diol 95 resulted in cleavage of the benzyl group and gave the title compound 96.

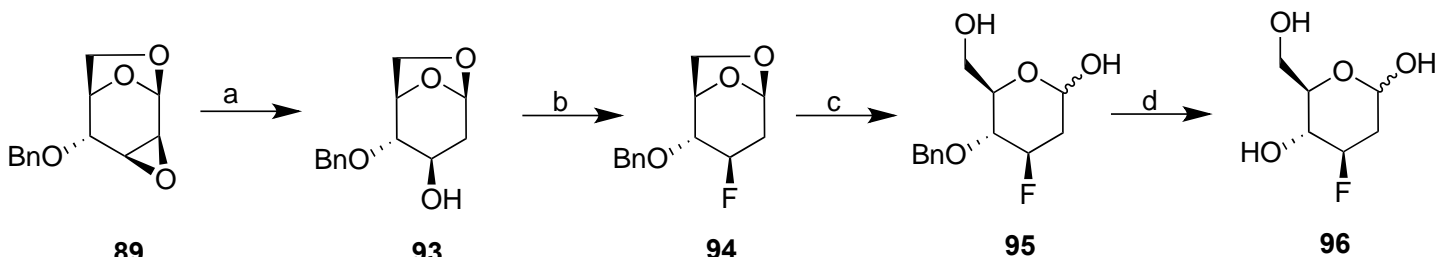

Scheme 32. Synthesis of 2,3-dideoxy-3-fluoro-D-glucose 96. Reagents/Conditions; (a) $\mathrm{LiAlH}_{4} / \mathrm{THF} / \mathrm{reflux} / 2 \mathrm{~h}$; (b) DAST/toluene/reflux/24h; (c) $1 \mathrm{M} \mathrm{H}_{2} \mathrm{SO}_{4} /$ dioxane/75 ${ }^{\circ} \mathrm{C}$; (d) $\mathrm{H}_{2} / \mathrm{Pd}(\mathrm{OH})_{2} / \mathrm{MeOH}$.

A de novo synthesis of trifluoroglucose $\mathbf{1 1 0}$ was reported by O'Hagan's group in an effort to provide a more expedient route to this target compound (Scheme 33). ${ }^{38}$ Butynediol 97 was monosilylated to afford butynyl silylether $\mathbf{9 8}$ which was then reduced to the TBDMS-protected trans-silyl ether $\mathbf{9 9}$. Sharpless epoxidation of $\mathbf{9 9}$ gave TBDMS-protected epoxyalcohol 100. Swern oxidation of $\mathbf{1 0 0}$ followed by Emmons-Horner olefination gave the TBDMS-protected $\alpha, \beta$-unsaturated epoxyester 101. Fluorinative epoxide ring-opening of 101 provided $\alpha, \beta$ unsaturated fluorodiol 102 which was protected to afford fluoroketal ester 103. Selective reduction of the ester function of $\mathbf{1 0 3}$ gave fluoro allylic alcohol 104 which was then epoxidized using the Sharpless method to fluoro epoxyalcohol 105. The alcohol group of $\mathbf{1 0 5}$ was protected to give the fluoro epoxy benzyl ether 106 with the dimethyl ketal intact. Fluorinative epoxide opening of benzyl ether 106 was done with hydrogen fluoride triethylamine to provide benzyl-protected difluoroalcohol 107. Deoxyfluorination of difluoroalcohol 107 to give benzyl-protected trifluoride 108 employed Deoxofluor ${ }^{\circledR}$ at $0 \stackrel{\circ}{ }{ }^{\circ}$. The benzyl group was removed from trifluoride 
108 giving trifluoroalcohol 109. Finally, 109 was oxidized and deprotected to give the target 2,3,4-trifluorosugar 110 (Scheme 33).

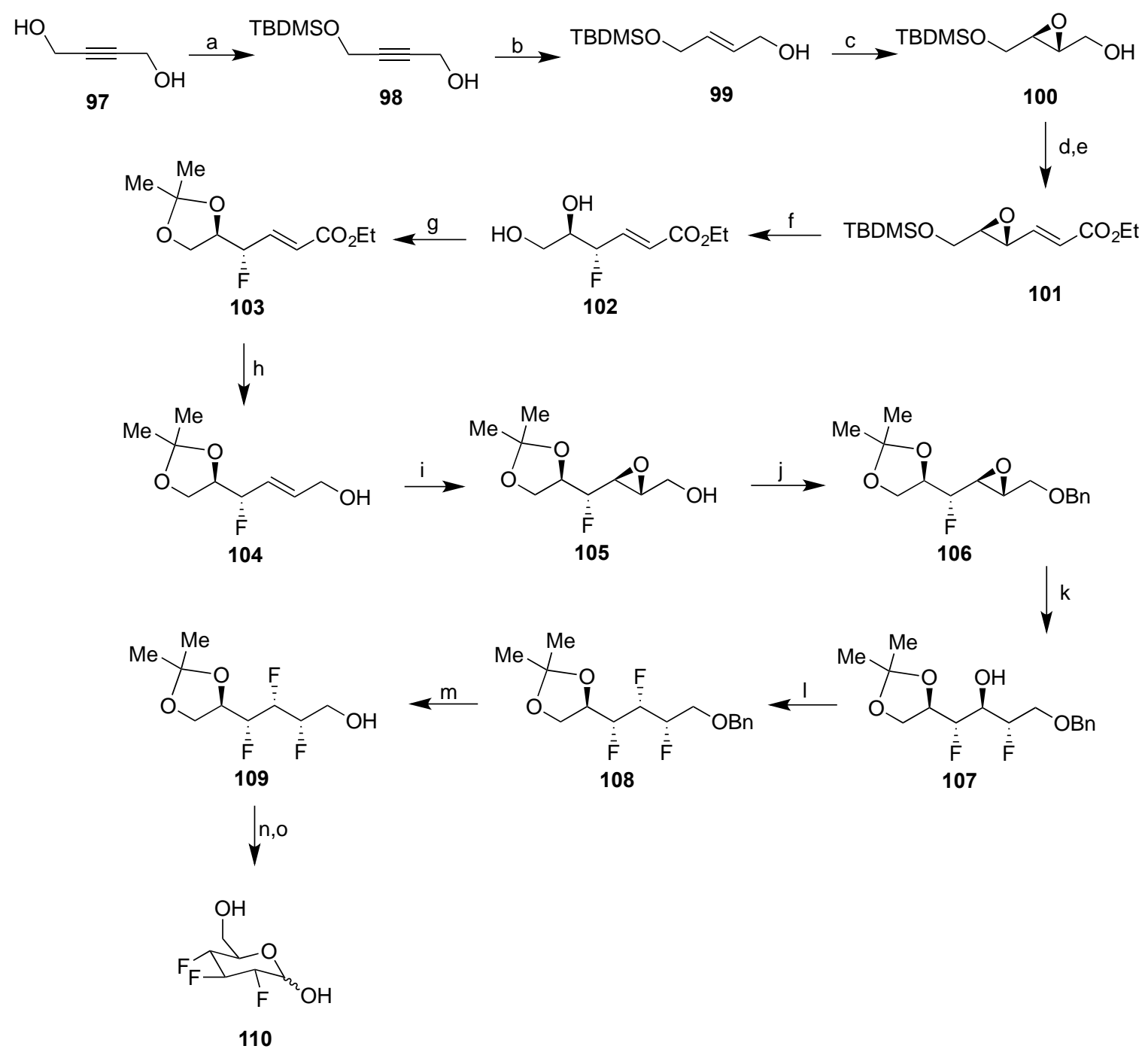

Scheme 33. Synthesis of trifluoroglucose 110. Reagents/Conditions: (a) TBDMSCl/ NaH/ THF/ $0{ }^{\circ} \mathrm{C}$ to RT / 18.5 h; (b) Red-Al/ THF/ $0{ }^{\circ} \mathrm{C}$ to RT/4 h; (c) Ti(OiPr) $4 /$ (-)-DIPT/ tBuOOH / DCM/4A MS $/ 25{ }^{\circ} \mathrm{C}$ to $-20{ }^{\circ} \mathrm{C} / 19.5 \mathrm{~h}$; (d) Oxalyl chloride/ DMSO/ NEt $3 / 78{ }^{\circ} \mathrm{C}$ to $0{ }^{\circ} \mathrm{C} / 2 \mathrm{~h}$; (e) $\mathrm{C}_{8} \mathrm{H}_{17} \mathrm{O}_{5} \mathrm{P} / \mathrm{NaH} / \mathrm{THF} / 0{ }^{\circ} \mathrm{C}$ to $78{ }^{\circ} \mathrm{C} / 2.5 \mathrm{~h}$; (f) $3 \mathrm{HF} \bullet \mathrm{NEt}_{3} / 90$ ${ }^{\circ} \mathrm{C} / 24 \mathrm{~h}$; (g) $\left(\mathrm{CH}_{3}\right)_{2} \mathrm{C}\left(\mathrm{OCH}_{3}\right)_{2} / \mathrm{CSA} / \mathrm{DMF} / \mathrm{RT} / 18 \mathrm{~h}$; (h) DIBAL-H/ THF/ $78{ }^{\circ} \mathrm{C}$ to RT; (i) Ti(OiPr) $4 /$ (-)-DIPT/ tBuOOH/ $\mathrm{DCM} / 4 \AA \mathrm{AS} / 25^{\circ} \mathrm{C}$ to $20{ }^{\circ} \mathrm{C} / 19.5$; (j) BnBr/ NaH/ DMF/ $0{ }^{\circ} \mathrm{C}$ to RT/ $18.5 \mathrm{~h}$; (k) $3 \mathrm{HF} \bullet \mathrm{NEt}_{3} / \mathrm{NEt}_{3} / 100{ }^{\circ} \mathrm{C} / 3$ days; (I) Deoxofluor ${ }^{\mathrm{TM}}$ (in THF)/ DCM/ $0{ }^{\circ} \mathrm{C}$ to RT/ $19 \mathrm{~h}$; (m) $\mathrm{NaBrO}_{3} / \mathrm{Na}_{2} \mathrm{~S}_{2} \mathrm{O}_{4} / \mathrm{H}_{2} \mathrm{O} / \mathrm{EtOAC} / \mathrm{RT} / 1.5 \mathrm{~h}$; (n) DMP/ DCM/ $0{ }^{\circ} \mathrm{C}$ to $\mathrm{RT} / 1 \mathrm{~h}$; (o) $\mathrm{SnCl}_{2} / \mathrm{DCM} / \mathrm{RT} / 1 \mathrm{~h}$.

\subsection{Pyranosides}

Carbohydrates, including sugars and fatty acids are widely abundant in the natural product arena, providing the energy sources for organisms through fueling their metabolism. Due to their biological activity, fluorinated nucleosides and their analogues are of interest in the science community-especially as antivirals. The substitution at the carbon-8 position has not received much attention, and the few that have been reported utilize the halex reaction with the substitution occurring by a bromine or a chlorine. Protected 8-fluoro 
derivatives of deoxyadenosine 111, deoxyinosine 114, and deoxyguanosine 117 via a direct metalationfluorination have been reported for the first time by Zajc and coworkers (Scheme 34). ${ }^{39}$

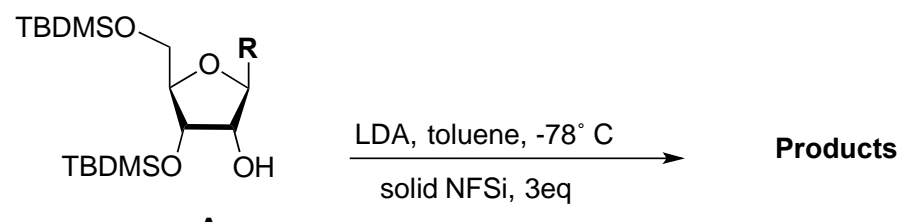

A<smiles>Cn1cnc2c(N)ncnc21</smiles><smiles>Cn1cnc2c(=O)[nH]cnc21</smiles><smiles>Cn1cnc2c(OCc3ccccc3)nc(N)nc21</smiles>

Scheme 34. Fluorination of purine nucleosides.

Protected 2'-deoxyadenosine $\mathbf{1 1 1}$ was fluorinated via metalation-electrophilic fluorination to form two fluorinated products that were separated by column chromatography. The fluorinated products were confirmed by ${ }^{19} \mathrm{~F}-\mathrm{NMR}$ and ${ }^{1} \mathrm{H}-\mathrm{NMR}$ and exhibited a fluorine resonance at $\delta 102.1 \mathrm{ppm} 112$ and $\delta 99.1 \mathrm{ppm}$ 113. The purine C8 proton resonance at $\delta 8.14 \mathrm{ppm}$ disappears with the fluorinated products, which was indicative of a protected 8-fluoroadenosine. Protected 2'-deoxyinosine $\mathbf{1 1 4}$ was also fluorinated via metalation-electrophilic fluorination to form 8-fluoro-2'-deoxyinosine $\mathbf{1 1 5}$ as the major product. $\mathbf{1 1 5}$ exhibited a fluorine resonance at $\delta$ $101.8 \mathrm{ppm}$ in the ${ }^{19} \mathrm{~F}-\mathrm{NMR}$; however, the minor product $\mathbf{1 1 6}$ did not display a fluorine resonance, but instead showed aromatic protons representing the phenyl ring in ${ }^{1} \mathrm{H}-\mathrm{NMR}$. Protected $\mathrm{O}^{6}$-benzyl 2'-deoxyguanosine 117 was fluorinated to form two fluorinated products, $\mathbf{1 1 8}$ and $\mathbf{1 1 9}$ that were separated by column chromatography and unfortunately very low yields of these were isolated.

Ritter's group fluorinated protected D-allofuranose $\mathbf{1 2 0}$ at C-3 by means of the deoxofluorinating reagent Phenofluor $^{\mathrm{TM}}$ in $83 \%$ yield and obtained the fluorosugar derivative $\mathbf{1 2 1}$ (Scheme 35). ${ }^{23}$

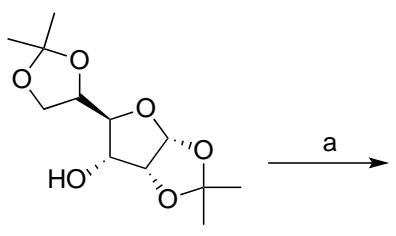

120

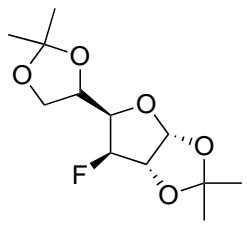

121 
Scheme 35. Fluorination of $D$-allofuranose 120. Reagents/Conditions: (a) Phenofluor ${ }^{\mathrm{TM}} / 2.0$ equiv. EtNiPr $2 / 2.0$ equiv. KF/ 2-20 h.

\section{General Oxygen Heterocycles}

\subsection{Furanoids/benzofuranoids}

Ascorbic acid 122, or better known as Vitamin C, is a compound well known to the science community as well as to the public. With research into the biochemistry involving ascorbic acid new insights have been revealed, including the information that the 6-hydroxy group is unimportant while the 2-hydroxy group is at the center of the reaction site in redox mechanisms of ascorbic acid. ${ }^{40}$ With this in mind chemical manipulation at the 2position of ascorbic acid can have an effect on the biological properties of this compound. 2-Fluoro-2-deoxy-Lascorbic acid 126 was prepared through halogenation of 2-deoxy-L-ascorbic acid $\mathbf{1 2 2}$ by Kirk and coworkers using NBS (Scheme 39). Fluorination of 123 using F-TEDA-BF 4 resulted in a 95\% yield of 124, in which reductive debromination using tri-n-butyltin hydride followed and resulted in the formation of 2-deoxy-2-fluoro-Labsorbic acid $\mathbf{1 2 6}$ after workup. Unfortunately, the desired 2-fluoro analogue $\mathbf{1 2 5}$ was not the sole product, and tautomerization between the enol 125 and the hemiketal 126 was a result, primarily due to the strong electronegativity of the fluorine atom (Scheme 36).

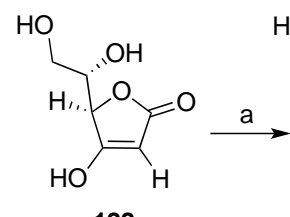

122

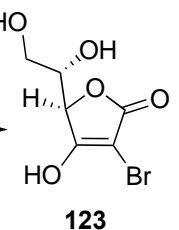

123

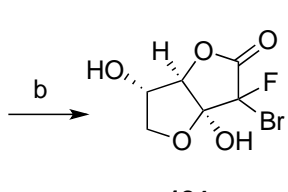

124

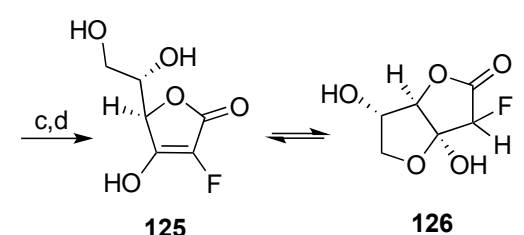

125
126

Scheme 39. Synthesis of fluorinated ascorbic acid 125. Reagents/Conditions: (a) NBS; (b) Selectfluor ${ }^{\circledR}$ THF; (c) $\mathrm{n}-\mathrm{Bu}_{3} \mathrm{SnH}$; (d) $10 \% \mathrm{HOAc}$.

\subsection{Pyranoids/benzopyranoids}

Flavones and chromones are found in many plants and are abundant chemical components of the human diet. ${ }^{41}$ These naturally occurring compounds are beneficial to the human body, decreasing the risks of multiple diseases. Unfortunately, recent studies have proven that these compounds have a very short lifetime in the body for 10 hours before being metabolized. With that in mind, Rozen's group examined the fluorination of flavones and chromones in an attempt to provide derivatives which are somewhat resistant to normal metabolic processes. ${ }^{41}$ Treatment of chromone 127 with fluorine gas resulted in a mixture of difluorinated products in which spontaneous elimination of hydrogen fluoride from intermediate $\mathbf{1 2 8}$ resulted in the formation of 3-fluorochromone $\mathbf{1 2 9}$ (Scheme 37). Fluorination of isoflavone 130 occurred similarly to that as $\mathbf{1 2 7}$ and gave fluoroisoflavone $\mathbf{1 3 2}$ through intermediate difluoride 131 (Scheme 38).

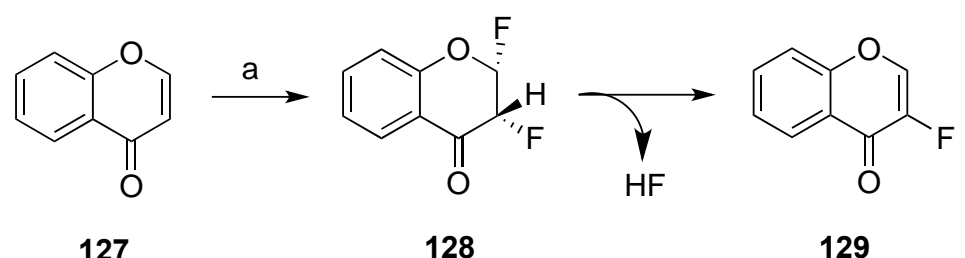


Scheme 37. Fluorination of chromone 127. Reagents/Conditions: (a) $F_{2} / N_{2}$.<smiles>O=c1cc(-c2ccccc2)oc2ccccc12</smiles>

130

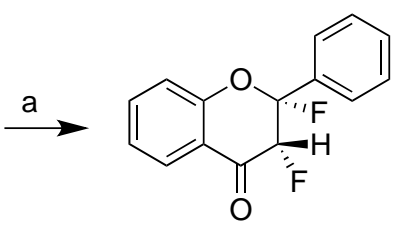

131

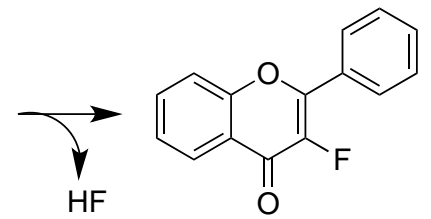

132

Scheme 38. Fluorination of isoflavanone 130. Reagents/Conditions: (a) $F_{2} / N_{2}$.

The fluorination of flavanone $\mathbf{1 3 3}$ was investigated by the Ritter group in 2010 and utilized the electrophilic fluorinating reagent, F-TEDA-PF 6 in the presence of a silver catalyst. The fluorination occurs on the aromatic ring to afford 134 as shown in Scheme 39. ${ }^{21}$

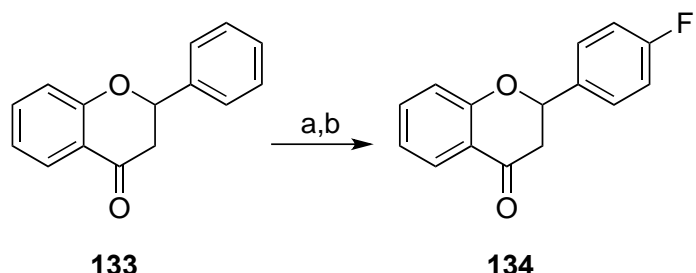

Scheme 39. Fluorination of flavanone 133. Reagents/Conditions: (a) 5.0 mol\% $\mathrm{Ag}_{2} \mathrm{O} / 2.0$ equiv $\mathrm{NaHCO}_{3} / 1.0$ equiv NaOTf; (b) 1.5 equiv F-TEDA-PF $6 /$ acetone $/ 65^{\circ} \mathrm{C}$.

\section{Aromatic Natural Products and Cyclic Ketones}

Acetophenone 135, a simple organic compound which occurs naturally occurring in certain foods, underwent an electrochemical aromatic fluorination as shown in Scheme $40 .{ }^{42}$ The main fluorination products were orthoand meta-isomers 136 and 137 respectively.

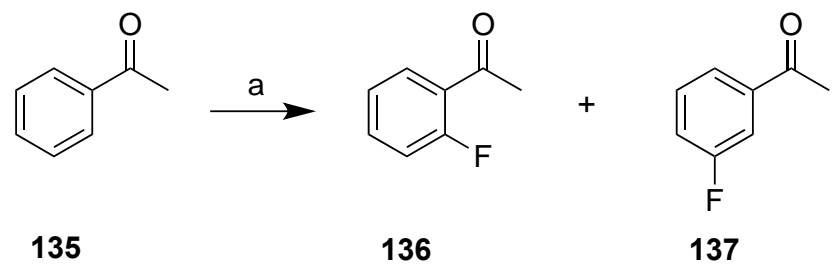

Scheme 40. Electrochemical fluorination of acetophenone 135. Reagents/Conditions: (a) anhydrous $\mathrm{HF} / \mathrm{CHCl}_{3}$ or $\mathrm{CH}_{3} \mathrm{CN}$.

A recent report from the O'Hagan group described the multistep de novo syntheses of nine civetone and five muscone analogues 138-140 containing the difluoromethylene motif. The fluorinated analogues were prepared for structure/conformation and odor comparisons. The key steps in the macrocycle synthesis utilized DAST for difluorination of intermediate carbonyls as well as Grubbs-type strategies to close the 15-17 membered rings. Some selected examples of O'Hagan's target compounds are shown in Figure $4 .{ }^{43}$ 


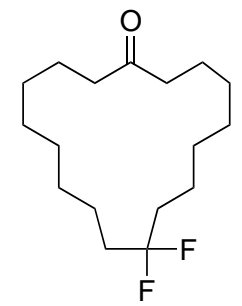

138

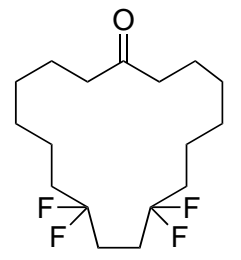

139

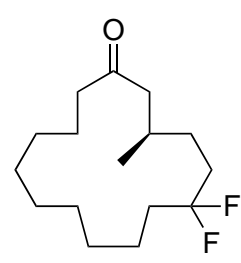

140

Figure 4. Fluorinated civetone 138, 130, and muscone 140 analogues.

\section{Amino acids and peptides}

Hunter's group recently investigated the stereoselective syntheses of $\alpha, \beta$-difluoro- $\gamma$-amino acids in order to provide a scalable reaction sequence. ${ }^{44}$ Deoxofluor ${ }^{\circledR}$ and HF in pyridine were employed in a series of reactions in order to provide new synthetic approaches toward the backbone-fluorinated amino acids 141 and 142 (Figure 5).

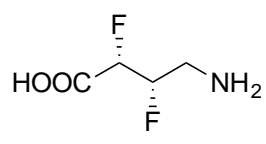

141

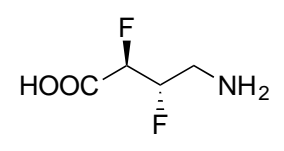

142

Figure 5. $\alpha, \beta$-Difluoro- $\gamma$-amino acids.

$\alpha, \beta$-Difluoro- $\gamma$-amino acid $\mathbf{1 4 2}$ was synthesized in a seven-step sequence and resulted in a vast improvement over previous synthetic ventures (Scheme 41). However, amino acid $\mathbf{1 4 1}$ is still under investigation to fully improve the synthesis, a venture which requires more steps, though still achieving good chemoselectivity. Cinnamyl alcohol 143 was stereoselectively epoxidized via the Sharpless method to afford epoxy alcohol 144. The $p$-toluenesulfonyl ester 145 of epoxyalcohol 144 was then prepared followed by fluorination of 145 to give tosyloxy-fluoroalcohol 146. Phthalimide displacement of 146 gave the $N$-phthalimdofluoroalcohol 147; or alternatively, fluorination of tosyloxy fluoroalcohol 146 gave the toxyloxy difluoride $\mathbf{1 4 8}$. Toward the common intermediate $N$-phthalimdodifluoride 149, the $N$-phthalimidofluoroalcohol 147 was fluorinated, or alternatively the tosyloxydifluoride 148 was submitted to phthalimide displacement. Finally, the phthalimide group of 149 was removed to obtain the $\alpha, \beta$-difluoro- $\gamma$-amino acid 142. 


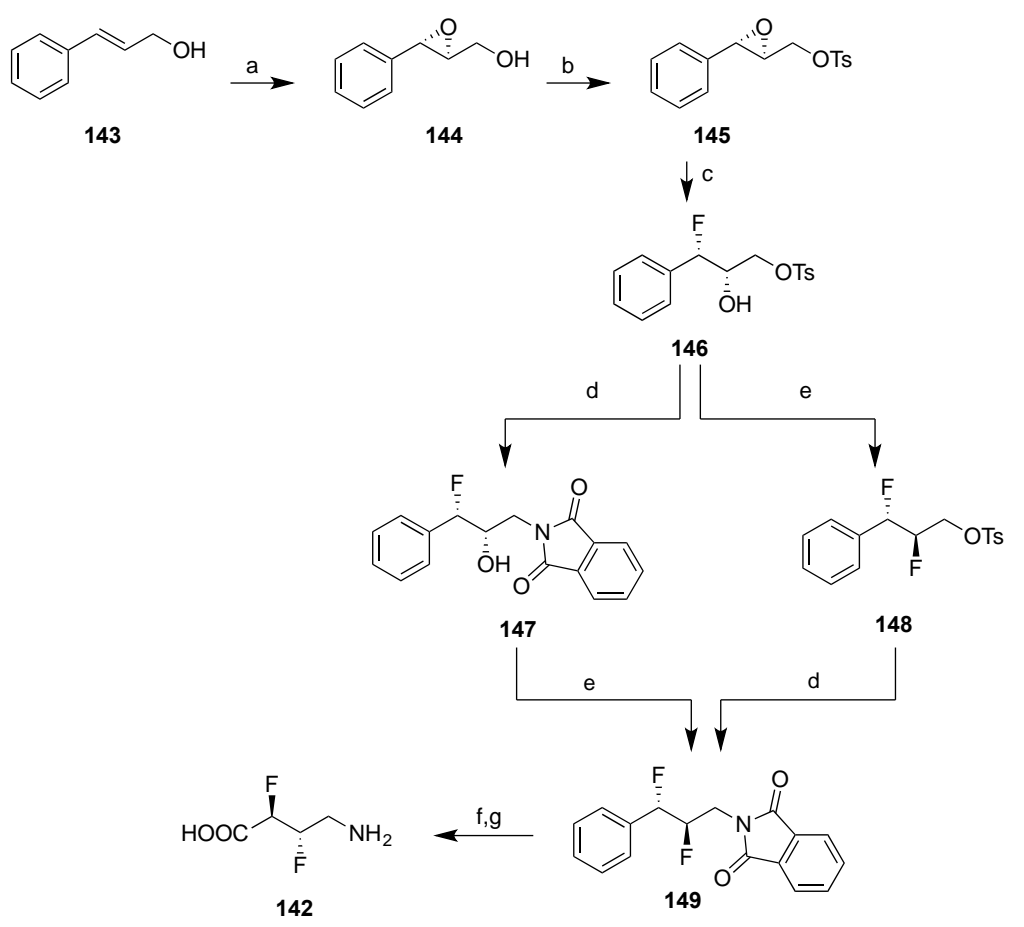

Scheme 41. Synthesis of $\alpha, \beta$-difluoro- $\gamma$-amino acid 142. Reagents/Conditions: (a) D-(-)-DET/t-BuOOH/Ti(Oi$\mathrm{Pr})_{4} / \mathrm{CH}_{2} \mathrm{Cl}_{2} /-20{ }^{\circ} \mathrm{C}$; (b) Et $\mathrm{Et}_{3} \mathrm{~N} / \mathrm{DMAP} / \mathrm{TsCl} / 0^{\circ} \mathrm{C}$; (c) $\mathrm{BF}_{3} \bullet \mathrm{OEt}_{2} / \mathrm{CH}_{2} \mathrm{Cl}_{2} /-20{ }^{\circ} \mathrm{C}$; (d) Deoxofluor ${ }^{\circ}$ (neat)/ $70{ }^{\circ} \mathrm{C}$; (e) phthalimide/potassium phtalimide/DMF/90 ${ }^{\circ} \mathrm{C}$; (f) $\mathrm{NaIO}_{4} / \mathrm{RuCl}_{3} / \mathrm{H}_{2} \mathrm{O} \mathrm{CH} \mathrm{Cl}_{2} / \mathrm{CH}_{3} \mathrm{CN} / \mathrm{RT}$; (g) $\mathrm{H}_{2} \mathrm{NNH}_{2} \bullet \mathrm{H}_{2} \mathrm{O} / \mathrm{EtOH} /$ reflux.

The cyclic peptide, maculosin $\mathbf{1 5 0}$ was fluorinated by Ritter's group in 2010 by utilizing F-TEDA-PF 6 in the presence of a silver catalyst, (Scheme 42). ${ }^{21}$ Maculosin is formed from tyrosine and proline and is a fungal and bacterial metabolite.

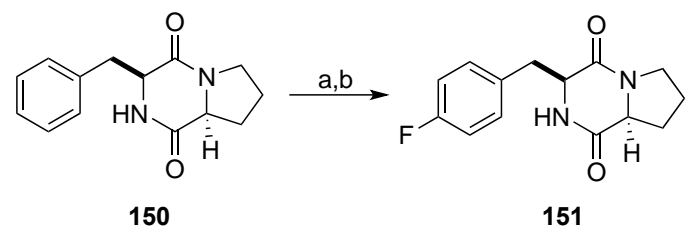

Scheme 42. Fluorination of maculosin 150. Reagents/Conditions: (a) 5.0 mol\% $\mathrm{Ag}_{2} \mathrm{O} / 2.0$ equiv $\mathrm{NaHCO}_{3} / 1.0$ equiv NaOTf; (b) 1.5 equiv F-TEDA-PF $6 /$ acetone $/ 65^{\circ} \mathrm{C}$.

\section{Alkaloids and Nitrogen Heterocycles}

Alkaloids are a large class of nitrogen-containing naturally occurring compounds which arguably have the greatest range of biological activities. Naturally-occurring quinine 152, one of the simpler alkaloids, was fluorinated by Ritter's group according to two different reports. ${ }^{21,}{ }^{22}$ Both reactions embody the use of an electrophilic fluorinating reagent, F-TEDA-PF 6 in the presence of a silver catalyst. The overall reaction provides for the addition of a fluoride atom to the 6'-position of the aromatic ring thereby giving analogue $\mathbf{1 5 3}$ (Scheme 43). 


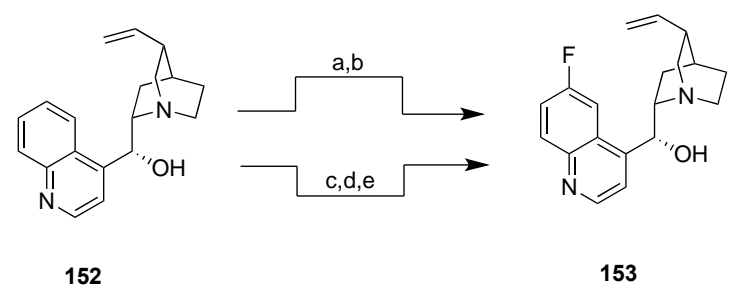

Scheme 43. Selective fluorination of quinine 152. Reagents/Conditions: (a) 20 mol\% AgOTf /2.0 equiv NaOTf; (b) 2.0 equiv F-TEDA-PF $6 /$ acetone $/ 90{ }^{\circ} \mathrm{C}$; (c) $\mathrm{Tf}_{2} \mathrm{O} / \mathrm{NEt}_{3}$; (d) $\mathrm{LiCl} / 5 \mathrm{~mol} \% \mathrm{Pd}\left(\mathrm{PPh}_{3}\right)_{4} /\left({ }^{\mathrm{B}} \mathrm{Bu}_{3} \mathrm{Sn}\right)_{2}$; (e) F-TEDA-PF 6 /AgOTf / acetone $/ 23^{\circ} \mathrm{C} / 20 \mathrm{~min}$.

Strychnine 154 was also selectively fluorinated by the Ritter group and utilized a similar protocol as that employed with quinine as described above (Scheme 44). ${ }^{21}$ Strychnine's structure was difficult for Ritter's group to fluorinate utilizing a silver catalyst due to the fact it doesn't contain a phenol functionality. Utilization of an in situ $\mathrm{N}$-benzylation followed by the silver-catalyzed fluorination resulted in an ammonium salt derivative of strychnine which immediately underwent hydrogenolysis yielding 2-fluorostrychnine 155 . The fluorination of camptothecin 156, another natural product with anticancer activity, was accomplished by utilizing Ritter's silver catalyzed fluorination approach as well and gave 10-fluorocamptothecin 157 (Scheme 45). ${ }^{22}$

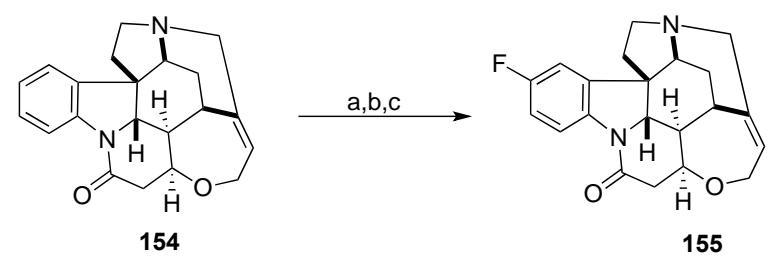

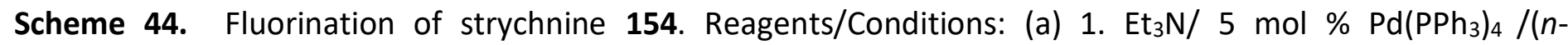
$\left.\mathrm{Bu}_{3} \mathrm{Sn}\right)_{2} /$ dioxane $/ 100{ }^{\circ} \mathrm{C}$; (b) BnBr/acetone/AgOTf/Ag $2 \mathrm{O}(5 \mathrm{~mol} \%) / \mathrm{NaHCO}_{3} / \mathrm{NaOTf} / \mathrm{F}-\mathrm{TEDA}-\mathrm{PF} 6 / 65^{\circ} \mathrm{C}$; (c) $1,4-$ cyclohexadiene/Pd/C/ MeOH/40 ${ }^{\circ} \mathrm{C} / 60 \%$ (2 steps).

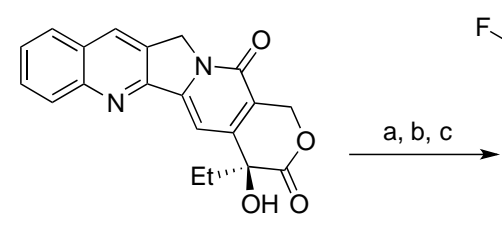

156

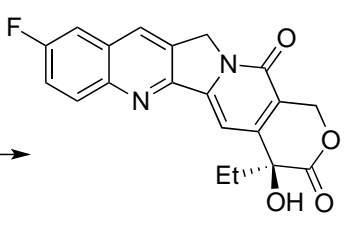

157

Scheme 45. Fluorination of camptothecin 156. Reagents/Conditions: (a) $\mathrm{Tf}_{2} \mathrm{O} / \mathrm{NEt}_{3}$; (b) LiCl/ $5 \mathrm{~mol} \%$ $\mathrm{Pd}\left(\mathrm{PPh}_{3}\right)_{4} /\left({ }^{\mathrm{B}} \mathrm{Bu}_{3} \mathrm{Sn}\right)_{2}$; (c) F-TEDA-PF $6 /$ AgOTf /acetone $/ 23^{\circ} \mathrm{C} / 20 \mathrm{~min}$.

Vinca alkaloids such as vinorelbine 158 are established useful chemotherapeutic agents, and the fluorinated derivatives of such compounds have been explored to optimize the therapeutic value of these natural products.

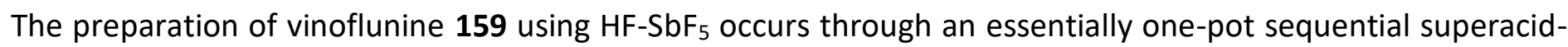
mediated chlorination at the allylic C-20' followed by sequential fluorination. Advantage was taken of the ability of the intermediate chloroalkyls, in the presence of superacids to form highly electrophilic intermediates where the nucleophilic fluoride can then attack (Scheme 46). ${ }^{45}$ 


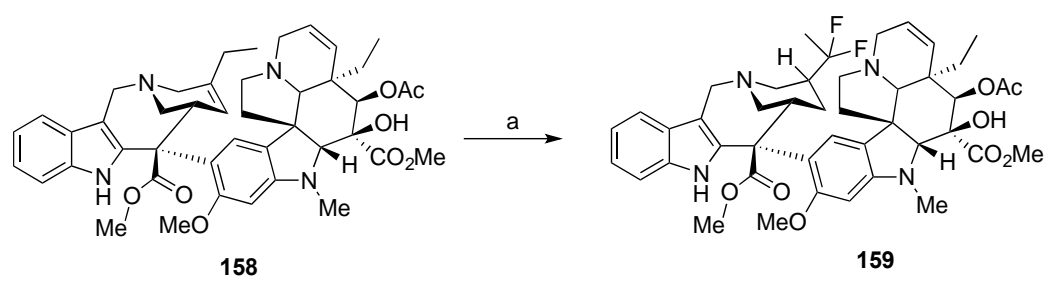

Scheme 46. Fluorination of vinorelbine 158. Reagents/ Conditions: (a) $\mathrm{HF}-\mathrm{SbF}_{5} / \mathrm{CCl}_{4} /-40{ }^{\circ} \mathrm{C}$.

Although Ritter's group successfully fluorinated multiple complex alkaloids utilizing a silver catalyzed fluorination reaction, they also fluorinated several complex alkaloids utilizing a nucleophilic, deoxygenating fluorinating reagent, phenofluor ${ }^{\mathrm{TM}}$. Ajmaline 160, morphine 162, galanthamine 164, and reserpine 166 were all complex alkaloids that were fluorinated using Phenofluor ${ }^{\mathrm{TM}}$ to provide fluorinated analogues $161,163,165$ and 167 (Scheme 47)..$^{23}$
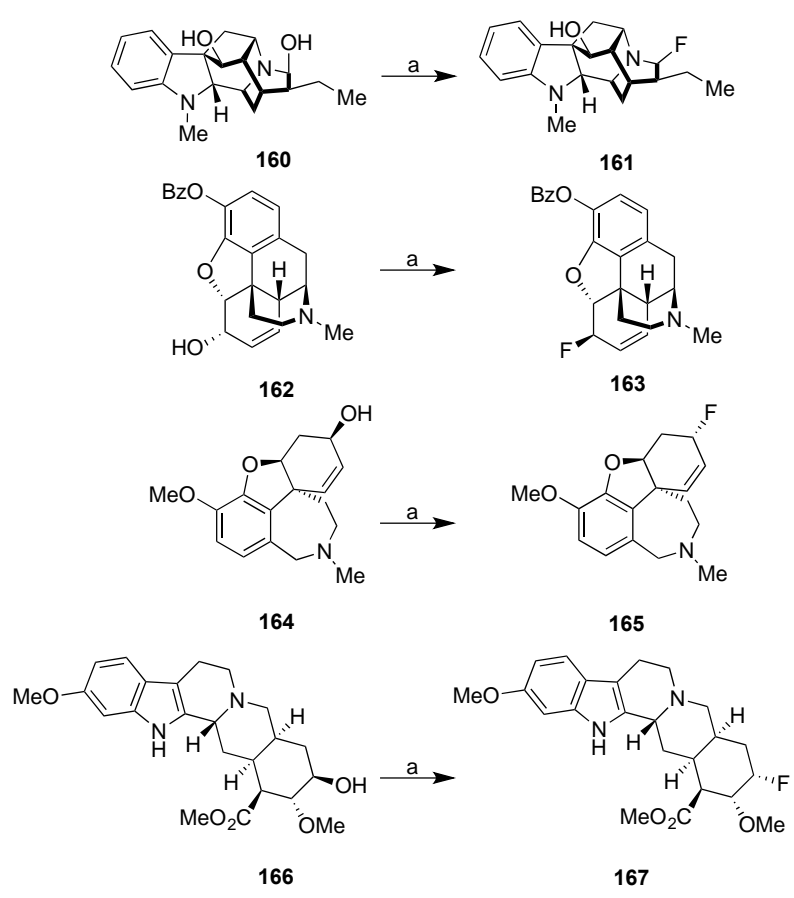

Scheme 51. Fluorination of ajmaline 160, morphine 162, galantamine 164, and reserpine 166. Reagents/Conditions: (a) Phenofluor ${ }^{\mathrm{TM}} / 2.0$ equiv EtN'Pr $2 / 2.0$ equiv KF/2-20 $\mathrm{h}$.

Both gypsetin 168, an inhibitor of acyl-Co-A cholesterol transferase, and brevianamide E 170, a cytotoxin, are two complex alkaloids which were both fluorinated. The strategy was to selectively replace the angular hydroxyl groups with angular fluorines thereby retaining stereochemistry in the fluorinated products 169 and 171 . The selective fluorinations of $\mathbf{1 6 8}$ and $\mathbf{1 7 0}$ utilized the electrophilic fluorination reagent, FP-T300 (Scheme 48). ${ }^{46}$ 


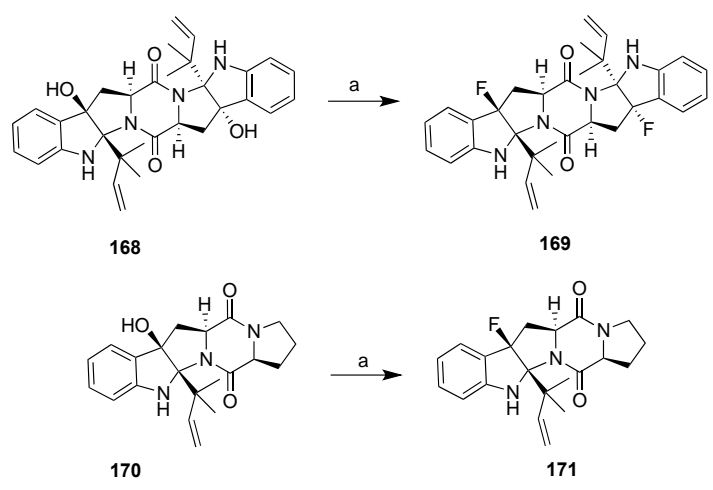

Scheme 48. Fluorination of gypsetin 168 and brevianamide E 170. Reagents/Conditions: (a) FP-T300/THF/65 ${ }^{\circ} \mathrm{C}$.

\section{Tannins/Lignans}

Podophyllotoxin 172, a non-alkaloid toxic lignan, is an effective topical treatment of external genital warts caused by the human papillomavirus (HPV). Podophyllotoxin was fluorinated using NFSI to form 2fluoropodophylotoxin 173. ${ }^{25}$ This potent antitumor agent was obtained by a completely diastereoselective fluorination of the sodium enolate formed with NFSI (Scheme 49).
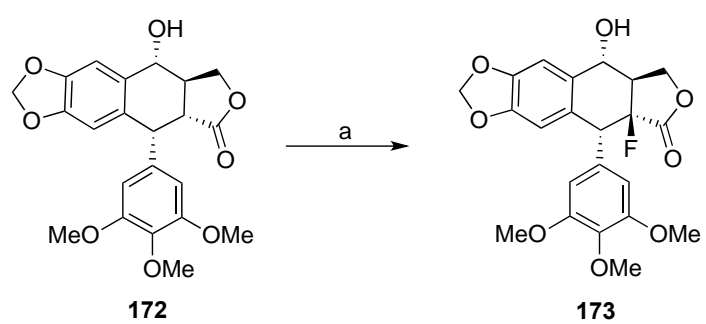

Scheme 49. Fluorination of podophyllotoxin 172. reagents/Conditions: (a) NFSI.

\section{Conclusions}

The synthesis and biological evaluation of fluorinated analogues and derivatives of natural products provides new in-roads in the field of medicinal chemistry and developmental therapeutics. Natural products are continuously being altered or modified in an effort to optimize their efficacy or probe their biochemical disposition. The development of new reactions and reagents have allowed for the fluorination of many sensitive substrates and have been useful on a drug discovery scale. On a manufacturing or otherwise process scale, the procedures for carbon-fluorine bond-forming reactions will still rely on older, more established technology due to costs and procedural ease. The examples of more recently employed techniques and strategy for the introduction of fluorine into natural products take into account the complexity of some of the chemical intermediates and late-stage substrates and may possibly be applied to starting materials used in the pharmaceutical industry once optimized. The selective fluorination of natural products has proven beneficial to date, and research will be continuing into the most prime 'areas' of fluorination of these complex molecules as the science advances. 


\section{References}

1. Corey, J. E.; Czakó, B.; Kürti, L. Molecules and Medicine; Wiley: New Jersey, 2007.

2. Uneyama, K. Organofluorine Chemistry; Blackwell: Oxford, 2006.

3. Kirsch, P.; Modern Fluoroorganic Chemistry: Synthesis, Reactivity, Applications, 2nd ed.; Wiley-VCH: Weinheim, 2013.

4. Isanbor, C.; O'Hagan, D.; J. Fluorine Chem. 2006, 127, 303-319. https://doi.org/10.1016/j.jfluchem.2006.01.011

5. Bégué, J-P.; Bonnet-Delpon, D.; J. Fluorine Chem. 2006, 127, 992-1012. https://doi.org/10.1016/i.jfluchem.2006.05.006

6. O'Hagan, D.; Harper, D.B.; J. Fluorine Chem. 1999, 100, 127-133.

https://doi.org/10.1016/S0022-1139(99)00201-8

7. Champagne, P. A.; Desroches, J.; Hamel, J.; Vandamme, M.; Paquin, J. Chem. Rev. 2015, 115, 9073-9174. https://doi.org/10.1021/cr500706a

8. Middleton, W. J. J. Org. Chem. 1975, 40, 574-578. https://doi.org/10.1021/jo00893a007

9. Lal, G. S.; Pez, G. P.; Pesaresi, R. J.; Prozonic, F. M.; Cheng, H. J. Org. Chem. 1999, 64, 7048- 7054. https://doi.org/10.1021/jo990566

10. Umemoto, T.; Singh, R. P.; Xu, Y.; Saito, N. J. Am. Chem. Soc. 2010, 132, 18199-18205. https://doi.org/10.1021/ja106343h

11. Tang, P.; Wang, W.; Ritter, T. J. Am. Chem. Soc. 2011, 133, 11482- 11484. https://doi.org/10.1021/ja2048072

12. Barton, D. H. R.; Ganguly, A. K.; Hesse, R. H.; Loo, S. N.; Pechet, M. M. Chem. Commun. 1968, 806-808. https://doi.org/10.1039/C19680000806

13. Liang, T.; Neumann, C. N.; Ritter, T. Angew. Chem. Int. Ed. 2013, 52, 8214-264. https://doi.org/10.1002/anie.201206566.

14. Umemoto, T.; Tomita, K. Tetrahedron Lett. 1986, 27, 3271 - 3274. https://doi.org/10.1016/S0040-4039(00)84772-3

15. Differding, E.; Ofner, H.; Synlett. 1991, 187-189. https://doi.org/10.1055/s-1991-20673

16. Banks, R. E.; Mohialdin-Khaffaf, S. N.; Lal, G. S.; Sharif, I.; Syvret, R. G. J. Chem. Commun. 1992, 595-596. https://doi.org/10.1039/C39920000595

17. Jin, Z.; Xu, B.; Dimagno, S. G.; Hammond, G. B. J. Fluorine Chem. 2012, 143, 226-230. https://doi.org/10.1016/j.jfluchem.2012.05.010

18. Halperin, S. D.; Fan, H.; Chang, S.; Martin, R. E.; Britton, R. Angew. Chem. Int. Ed. 2014, 53, 4690-4693. https://doi.org/10.1002/anie.201400420

19. Keyser, G.E. U.S. Patent 5510 544, 1993.

20. Abad, A.; Consuelo, A.; Cuñat, A. C.; González-Coloma, A.; Pardo, D. Eur. J. Org. Chem. 2010, 2182-2198. https://doi.org/10.1002/ejoc.200901499

21. Tang, P.; Furuya, T.; Ritter, T. J. Am. Chem. Soc. 2010, 132, 12150-12154. https://doi.org/10.1021/ja105834t

22. Furuya, T.; Storm, A. E.; Ritter, T. J. Am. Chem. Soc. 2009, 131, 1662-1663. https://doi.org/10.1021/ja8086664 
23. Sladojevich, F.; Arlow, S. I.; Tang, P.; Ritter, T. J. Am. Chem. Soc. 2013, 135, 2470-2473. https://doi.org/10.1021/ja3125405

24. Liu, W.; Xiongyi, H.; Cheng, M.; Nielsen, R. J.; Goddard III, W. A.; Groves, J. T. Science. 2012, 337, 13221325.

https://doi.org/10.1126/science.1224953

25. Ma, J.; Cahard, D. Chem. Rev. 2004, 104, 6119-6146. https://doi.org/10.1021/cr030143e

26. Mansurova, M.; Klusák, V.; Nešněrová, P.; Muck, A.; Doubský, J.; Svatoš, A. Tetrahedron. 2009, 65, 10691076. https://doi.org/10.1016/j.tet.2008.10.106

27. Ambrosi, P.; Arnone, A.; Bravo, P.; Bruché, L.; Cristofaro, A. D.; Francardi, V.; Frigerio, M.; Gatti, E.; Germinara, G. S.; Panzeri, W.; Pennacchio, F.; Pesenti, C.; Rotundo, G.; Roversi, P. F.; Salvadori, C.; Viani, F.; Zanda, M. J. Org. Chem. 2001, 66, 8336-8343.

https://doi.org/10.1021/jo0055640

28. Chiang, C.; Ramu, R.; Tu, Y.; Yang, C.; Ng, K.Y.; Luo, W.; Lu, y.; Liu, C.; Yu, S. S. Chem. Eur. J. 2013, 19, 13680-13691.

https://doi.org/10.1002/chem.201302402

29. Monsen, P. J.; Luzzio, F A. unpublished results.

30. Jasem, Y. A.; Thiemann, T.; Gano, L.; Oliveira, M.C. J. Fluorine Chem. 2016, 185, 48-85. https://doi.org/10.1016/i.jfluchem.2016.03.009

31. Bogautdinov, R. P.; Fidarov, A. F.; Morozkina, S. N.; Zolotarev, A. A.; Starova, G. L.; Selivanov, A. I.; Shavva, A. G. J. Fluorine Chem. 2014, 168, 218-222.

https://doi.org/10.1016/i.jfluchem.2014.09.030

32. Heravi, M. R. P. J. Fluorine Chem. 2008, 129, 217-221.

https://doi.org/10.1016/i.jfluchem.2007.11.006

33. Kwiatkowoski, P.; Beeson, T. D.; Conrad J. C.; MacMillan, D. W. C. J. Am. Chem. Soc. 2011, 133, 1738-1741. https://doi.org/10.1021/ja111163u

34. Königsberger, K.; Chen, G.; Vivelo, J.; Lee, G.; Fitt, J.; McKenna, J.; Jenson, T.; Prasad, K.; Repic, O. Org. Process Res. Dev. 2002, 6, 665-669.

https://doi.org/10.1021/op0255433

35. Roberto, P. Eur. Pat. Appl. 3934931995

36. Meinke, P. T.; Shoop, W. L.; Michael, B. F.; Blizzard, T. A.; Dawson, G. R.; Fisher, M. H.; Mrozik, H. Bioorg. Med. Chem. Lett. 1998, 8, 3643-3646.

https://doi.org/10.1021/jo962394b

37. Mtashobya, L.; Quiquempoix, L.; Linclau, B. J. Fluorine Chem. 2015, 171, 92-96.

https://doi.org/10.1016/j.jfluchem.2014.08.023

38. Corr, M. J.; O'Hagan, D. J. Fluorine Chem. 2013, 155, 72-77.

https://doi.org/10.1016/j.jfluchem.2013.06.003

39. Ghosh, A. K.; Lagisetty, P.; Zajc, B. J. Org. Chem. 2007, 72, 8222-8226.

https://doi.org/10.1021/jo0711211

40. Ge, P.; Kirk, K. L. J. Org. Chem. 1997, 62, 3340-3343.

https://doi.org/10.1021/jo962394b

41. Vints, I.; Rozen, S. J. Org. Chem. 2014, 79, 7261-7265. 


\section{https://doi.org/10.1021/j05009542}

42. Shainyan, B.A.; Danilevich, Y.S.; Grigor'eva, A.A.; Chuvashev, Y.A. Russian Journal of Organic Chemistry. 2003, 39, 11, 1581-1586.

https://doi.org/10.1023/B:RUJO.0000013131.19936.5e

43. Callejo, R.; Corr, M. J.; Yang, M.; Wang, M.; Cordes, D. B.; Slawin, A. M. Z.; O'Hagan, D. Chem. Eur. J. 2016, 22, 8137-8151.

44. Patel, A. R.; Hu, X.-G.; Lawer, A.; Ahmed, M. I.; Au, C.; Jwad, R.; Trinh, J.; Gonzalez, C.; Hannah, E.; Bhadbhade, M. M.; Hunter, L. Tetrahedron. 2016, 72, 3305-3317.

https://doi.org/10.1016/j.tet.2016.04.070

45. Kirk, K.L. Org. Process Res. Dev. 2008, 12, 305-321.

https://doi.org/10.1021/op700134j

46. Shibata, N.; Tarui, T.; Doi, Y.; Kirk, K.L. Angew. Chem. Int. Ed. 2001, 40, 4461-4463.

https://doi.org/10.1002/1521-3757(20011203)113:23<4593::AID-ANGE4593>3.0.CO;2-8

\section{Authors Biographies}

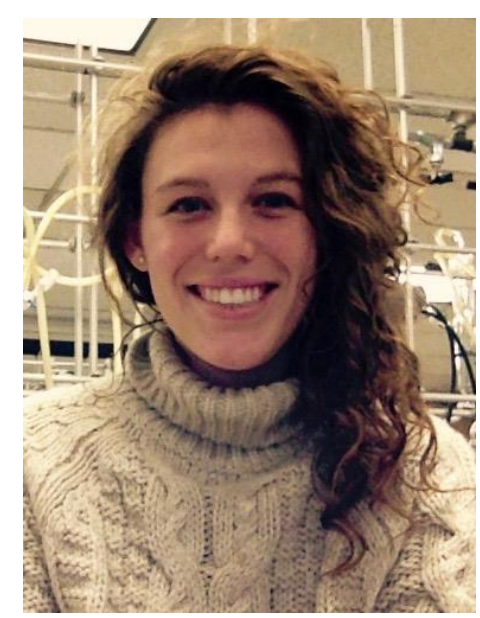

Paige Monsen was born in 1993 in Cortland, New York. She received her Bachelor's degree in chemistry from the University of Louisville in 2015. She entered the Ph.D. graduate program at the University of Louisville the following semester, joining the group of Dr. Frederick Luzzio where she is currently working as a Ph.D. student. Her research interests are focused on the natural compound annonacin which is isolated from the pawpaw, a fruit native to the area. 


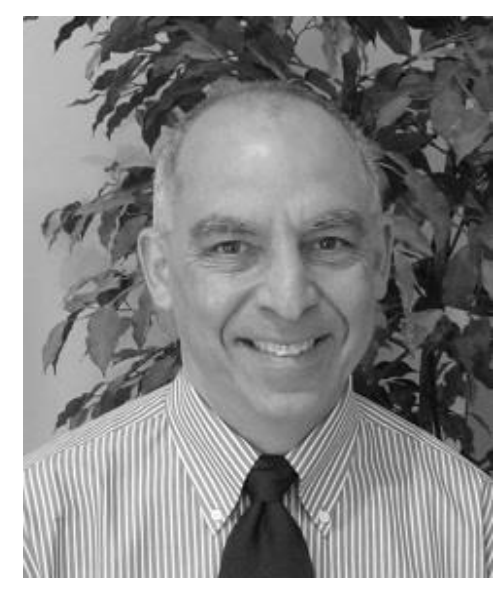

Frederick Luzzio was born in Lawrence, Massachusetts and raised near Ft. Knox, Kentucky. He graduated from Vanderbilt University (BS, 1976) where he majored in chemistry and biology. He worked as a development chemist at Arthur D. Little, Inc. in Cambridge, Massachusetts until entering Tufts University where he earned his MSc and PhD degrees in organic chemistry under the mentorship of Frank S. Guziec, Jr. After finishing graduate study, he spent three years of study with Professor E. J. Corey as a post-doctoral fellow, followed by two years in the Biomedical Products Department of DuPont. Since 1988 he has served on the faculty of the University of Louisville where he is currently Professor. His research interests are in the areas of organic synthesis, natural products and medicinal chemistry. 